\title{
Scatter of Constitutive Models of the Mechanical Properties of Concrete: Comparison of Major International Codes
}

\author{
João Pacheco ${ }^{*}$, Jorge de Brito ${ }^{2}$, Carlos Chastre $^{3}$ and Luís Evangelista4 ${ }^{4}$
}

\begin{abstract}
An investigation on the scatter of code-type constitutive models that relate compressive strength $\left(f_{c}\right)$ with tensile strength $\left(f_{c t}\right)$ and Young's modulus $\left(E_{c}\right)$ of standard concrete specimens is presented. The influence of the mix design on the accuracy of the $f_{c}$ vs. $f_{c t}$ and $f_{c} v s . E_{c}$ relationships is discussed, with emphasis on the lithological type and morphology of the coarse aggregates. The uncertainty of the constitutive models is analysed in probabilistic terms and random variables that model the uncertainty of the $f_{c} v s . f_{c t}$ and $f_{c} v s . E_{c}$ relationships are proposed for reliability analyses of serviceability limit states. The suitability of the models proposed is assessed through preliminary conservative estimates of their design values.
\end{abstract}

\section{Introduction}

Concrete codes and standards of quality control are mostly concerned with concrete's compressive strength $\left(f_{c}\right)$. The other properties are usually estimated through constitutive models. Since codes are developed with emphasis on applicability, the same constitutive models are used for concrete produced with very different materials and mix design when in fact differences in constitutive relationships may be significant. This is a particularly relevant fact since in most construction works only $f_{c}$ is tested and the other concrete properties may never be known.

This paper analyses the model uncertainty $(\theta)$ of the constitutive relationships between $f_{c}$ and Young's modulus $\left(E_{c}\right)$ and between $f_{c}$ and tensile strength $\left(f_{c t}\right)$ in different documents. Equation (1) illustrates the concept of $\theta$ for $E_{c}$.

${ }^{1} \mathrm{PhD}$ Candidate in Civil Engineering, CERIS-ICIST, Department of Civil Engineering, Architecture and Georresources, Instituto Superior Técnico, Universidade de Lisboa, Av. Rovisco Pais, 1049-001 Lisbon, Portugal. *Corresponding author, E-mail: joaonpacheco@ist.utl.pt ${ }^{2}$ Full Professor, CERIS-ICIST, Department of Civil Engineering, Architecture and Georresources, Instituto Superior Técnico, Universidade de Lisboa, Av. Rovisco Pais, 1049-001 Lisbon, Portugal.

${ }^{3}$ Associate Professor, CERIS-ICIST and Department of Civil Engineering, Faculdade de Ciências e Tecnologia, Universidade Nova de Lisboa, 2829-516 Caparica, Portugal.

${ }^{4}$ Assistant Professor, CERIS-ICIST, ISEL, Department of Civil Engineering, Instituto Superior de Engenharia de Lisboa, Rua Conselheiro Emídio Navarro, 1, 1959007 Lisbon, Portugal.

$$
\theta_{E}=\frac{\text { Experimental } E_{c}}{\text { Constitutive mod el estimate of } E_{c}}
$$

If the model uncertainties of $E_{c}\left(\theta_{E}\right)$ and/or of $f_{c t}$ $\left(\theta_{f c t}\right)$ significantly change, this means that some concrete mix designs will result in structures with serviceability and ultimate limit-states behaviour that may differ from that foreseen by the codes.

Concrete technology has been developing steadily over the last decades and the advent of new types of concrete increased the range of concrete mixes used. The same concrete codes are applicable to mixes with very different admixtures, binder blends, and specified $f_{c}$. Materials such as superplasticizers and waste materials (silica fume - SF, recycled aggregates, fly ash - FA, ground granulated blast-furnace slag - GGBS, and others) are becoming increasingly popular and their influence on concrete and cement paste properties affects the microstructure and behaviour of concrete, influencing the constitutive relationships (Alexander and Milne 1995; Bravo et al. 2015b; Saito and Kawamura 1989). The incorporation of FA and GGBS is noteworthy: most concrete produced in developed countries nowadays includes either of these materials, but the constitutive models of codes treat these types of concrete (and all others) in the same way as concrete with ordinary Portland cement (OPC) blend.

\section{Reesearch goals and significance}

This paper intends to investigate whether different mix designs and strength ranges will result in different accuracy and precision of the $\theta$ of the $f_{c} v s f_{c t}$ and $f_{c} v s$. $E_{c}$ relationships. The main objective of the paper is the proposal of probability distributions of $\theta_{E}$ and $\theta_{f c t}$ intended for serviceability limit-state (SLS) reliability analyses.

Coefficients $\theta_{E}$ and $\theta_{f c t}$ are calculated as shown in 
Table 1 Constitutive models.

\begin{tabular}{|l|l|c|}
\hline Tensile strength: & \multicolumn{2}{|l|}{} \\
\hline Eurocode 2 (2008) and Model Code 2010 & $f_{c t m}=0.30\left(f_{c m}-8\right)^{2 / 3}$ if strength class $\leq C 50$ & (2) \\
& $f_{c t m}=2.12 \ln \left\{\left(1+f_{c m} / 10\right)\right\}$ if strength class $>C 50$ & \\
\hline Eurocode 2 (2020) & $f_{c t m}=0.30\left(f_{c m}-8\right)^{2 / 3}$ if strength class $\leq C 50$ & $(3)$ \\
& $f_{c t m}=1.10\left(f_{c m}-8\right)^{1 / 3}$ if strength class $>C 50$ & $(4)$ \\
\hline ACI 318 & $f_{c t m, s p l t}=0.56\left(f_{c m}\right)^{1 / 2}$ & $(5)$ \\
\hline Young's modulus: & $E_{c m}=\alpha 22000\left\{f_{c m} / 10\right\}^{0.3}$ & $(6)$ \\
\hline Eurocode 2 (2008) & $E_{c m}=\alpha 21500\left\{f_{c m} / 10\right\}^{1 / 3}$ & $(7)$ \\
\hline Model Code 2010 & $E_{c m}=\alpha 10000 f_{c m}^{1 / 3}$ & $(8)$ \\
\hline Eurocode 2 (2020) & $E_{c m}=4700\left(f_{c m}\right)^{1 / 2}$ & \\
\hline ACI 318 &
\end{tabular}

Equation (1) from 28-day test data from several publications and mix designs and probabilistic models are then developed for both $\theta_{E}$ and $\theta_{f c t}$.

Current SLS reliability analyses are hindered since the only concrete property specified in common construction projects is the characteristic compressive strength $\left(f_{c k}\right)$ and most SLS are related to crack or deflection control. The actual $E_{c}$ and $f_{c t}$ are quite uncertain. Since probabilistic conversion models from expected to actual properties are lacking - the only study on this subject known to the authors dates from 1979 (Mirza et al. 1979), publications on the reliability of the SLS of concrete (Honfi et al. 2012) neglect this source of uncertainty with obvious consequences on the estimates of the probabilities of failure of SLS. This is a very relevant absence in the state-of-the-art of structural concrete and hinders, for instance, the reliability-based calibration of SLS code verifications.

The ultimate goals of the paper are:

1. Quantification of the statistics of $\theta_{E}$ and $\theta_{f c t}$ of codes;

2. Analysis of the influence of different mix designs on $\theta_{E}$ and $\theta_{f c t}$, with emphasis on the coarse aggregates used, including recycled concrete aggregates;

3. Development of probabilistic models for $\theta_{E}$ and $\theta_{f c t}$, intended for reliability analyses related to the deflections and cracking calculations of SLS.

The relationships analysed are those of ACI 318 (2014), the current version of Eurocode 2 (2008), Model Code 2010 ( $f i b$ 2010), and the October 2017 draft of the Eurocode 2 revision with expected publication in 2020, herein named Eurocode 2 (2020).

The mechanical properties of concrete are frequently tested in $\phi 100 \mathrm{~mm} \times 200 \mathrm{~mm}$ cylinders instead of in the cylinder size of standards $(\phi 150 \mathrm{~mm} \times 300 \mathrm{~mm})$. Since some standards (ASTM-C31M 2003) treat the $f_{c}$ of $\phi 100 \mathrm{~mm} \times 200 \mathrm{~mm}$ cylinders as if $\phi 150 \mathrm{~mm} \times$ $300 \mathrm{~mm}$ had been tested, $\theta$ is analysed for both cylinder sizes and the applicability of constitutive models with $f_{c}$ data coming from $\phi 100 \mathrm{~mm}$ x $200 \mathrm{~mm}$ cylinders is discussed.
Concrete is a highly complex and heterogeneous material that can be produced with very different materials and proportioning. This means that models that would predict the $\theta_{E}$ and $\theta_{f c t}$ accurately are not possible. The aim of the paper is the definition of suitable models that estimate $\theta_{E}$ and $\theta_{f c t}$ within a reasonable margin and within the scope of serviceability reliability analyses. As stated in codes, if $E_{c}$ and/or $f_{c t}$ are important in ultimate limit state design, specific testing should be made.

Also because of the variability in concrete mix design, the specific influence of aggregate type (or other parameters) cannot be fully accounted for, since the concrete mix design of each individual study is biased towards the regional practice and materials of the laboratory were that study was made. Research concerning the influence of specific parameters (such as strength class, binder blend, and type of aggregate) on the constitutive models of concrete should be analysed through individual laboratory tests, were the other mix design parameters can be kept constant.

\section{Methodology}

\subsection{Code-type models}

Equations (2) - (8) are written in Table 1 and show the constitutive models analysed. A notations table, provided in a separate section of the paper, states the meanings of each symbol. All units are in MPa. The models of Model Code 2010 and both Eurocode versions are very similar.

The $\alpha$ factor of Equations (5) - (7) depends on the nature of the aggregates: 1.0 for quartzite aggregates, 1.2 for basalt, 0.7 for sandstone, and 0.9 for limestone aggregates. Since current codes have no clauses for recycled aggregate concrete properties, recycled concrete aggregate was analysed with an $\alpha$ factor of 0.7 , as argued for by Silva et al. (2016). Since the objective of the paper is determining the accuracy of the $\theta$ of codes, rather than proposing new code-type models, the $\alpha$ factors will be used as specified in codes even if more suitable values could be found. The formula of ACI 318 
(2014) has no $\alpha$ factor and does not account for the type of aggregate.

References to the characteristic compressive strength $\left(f_{c k}\right)$ were converted to the average compressive strength $\left(f_{c m}\right)$ in Equations (2) - (3). As specifically recommended in Eurocode 2 (2008), Eurocode 2 (2020), and Model Code 2010, $f_{c m}$ was considered as $f_{c K}+8$ MPa.

Equation (4) concerns the splitting tensile strength, whilst Equations $(2)-(3)$ estimate the uniaxial $f_{c t}$. All experimental data appraised on the paper concern splitting tensile strength tests and the $\theta_{f c t}$ analysis will be made as if splitting tensile strength data were equivalent to those of uniaxial $f_{c t}$. This option was made because splitting tensile tests are by far the most common type of experimental test on $f_{c t}$. Conceptually, the uniaxial tensile strength is a more correct test, but is highly sensitive to the experimental setup and heterogeneities of specimens (Bažant and Cedolin 1993). Malárics and Muller (2010) performed extensive research and argue in favour of converting splitting tensile strength data into uniaxial $f_{c t}$ data using a factor of 1.0. Model Code 2010 also follows this recommendation (fib 2013).

\subsection{Types of analysis}

$\theta_{E}$ and $\theta_{f c t}$ in the constitutive models of the four documents are calculated using Equations (2) - (8) for each concrete mix appraised and the following analyses are made:

1. Influence of the aggregate type on the statistics of $\theta_{E}$

2. Influence of the aggregate morphology on the statistics of $\theta_{f c t}$;

3. Influence of $f_{c}$ on $\theta_{E}$ and $\theta_{f c t}$;

4. Goodness-of-fit testing of lognormal and normal distributions for $\theta_{E}$ and $\theta_{f c t}$;

5. Definition of suitable probability distributions for $\theta_{E}$ and $\theta_{f c t}$;

6. Assessment of the errors of the proposed probability distributions in comparison to the actual data within an SLS framework.

The type of the coarse aggregate is arguably the most relevant parameter that determines the $f_{c} v s$. $E_{c}$ relationship (Alexander 1996; fib 2013; Kliszczewicz and Ajdukiewicz 2002). Limestone (LS), sandstone (SS), basalt (BS), granite (GR), quartzite (QZ), and recycled concrete aggregates (RA) were analysed. The five types of natural aggregates are the most commonly used aggregates in concrete technology, whilst RA are the most common type of recycled aggregates. The incorporation of RA affects $\theta_{E}$ since its high deformability has a more relevant effect on $E$ than on $f_{c}$ (Silva et al. 2016).

Coefficient $\theta_{f c t}$ is analysed in terms of three coarse aggregate morphologies: crushed natural aggregates (CNA), rounded natural aggregates (RNA), and crushed recycled aggregates (CRA). These aggregate morphologies result in different interfacial transition zones (ITZ) between the coarse aggregates and the cementitious paste (fib 2013; Sidorova et al. 2014).

The specified strength class may influence $\theta_{E}$ and $\theta_{f c t}$ since $f_{c}$ increases are related to stiffer and stronger cement pastes, which increases the dependence of $E_{c}$ and $f_{c t}$ on aggregate characteristics (Bravo et al. 2017; $f i b$ 2008). Within the high-strength concrete range ( $f_{c}$ above $50 \mathrm{MPa}$ ), the deformability of the cementitious paste becomes similar to that of the aggregates and a relevant number of trans-aggregate fractures occur on the failure surface of specimens ( $f i b$ 2013).

Admixtures influence the microstructural properties of concrete, particularly in the ITZ region (Saito and Kawamura 1989), and they are expected to affect both the $\theta_{E}$ and $\theta_{f c t}$ relationships (Mehta and Monteiro 2006).

Because of the dependence of the $f_{c} v s . f_{c t}$ and $f_{c} v s$. $E_{c}$ relationships on all these factors, the statistics of $\theta_{E}$ and $\theta_{f c t}$ are analysed by subpopulations split by strength range and aggregate lithology/morphology. Scatterplots that show the blinder blend of each mix are also plotted and considered in the analysis. The relevance of each subpopulation is judged considering its particular mix designs.

\subsection{Database criteria}

Data were appraised from publications in which $f_{c}, E_{c}$ and/or $f_{c t}$ were obtained from the same concrete batch. Data from cylinders of different size (either $\phi 150 \mathrm{x}$ $300 \mathrm{~mm}$ or $\phi 100 \times 200 \mathrm{~mm}$ ) were not mixed and conversions from experiments on specimens with other dimensions were not made since such conversions are highly scattered and dependent on the type of coarse aggregate used (Pacheco et al. 2019b). All data concern tests performed at 28 days.

Mixes with RA enhanced by beneficiation techniques were not included in the database. Only RA concrete with total RA incorporation was analysed, since data on intermediate replacements of natural aggregates by RA are not as numerous. Some references concern properties of concrete exposed to high temperatures but only tests on control specimens subjected to normal temperatures were analysed.

Self-compacting concrete mixes were not collected since this type of concrete is associated with binder contents, $w / b$ ratios, and binder blends that differ from traditional concrete mix design. Since self-compacting concrete is specified during design, specific models for its $\theta$ relationships should be developed separately and used explicitly when analysing the behaviour of selfcompacting concrete.

Figures 1 and $\mathbf{2}$ show the distribution of concrete mixes by aggregate nature $\left(E_{c}\right)$ and aggregate morphology $\left(f_{c t}\right)$.

The sources of the $f_{c} v s$. $E_{c}$ data were the following:

- $\phi \quad 150 \mathrm{~mm}$ cylinders: Ajdukiewicz and Kliszczewicz (2002, 2007), Atahan et al. (2011), Bilodeau and Malhotra (1992), Bravo et al. 
(2015a), Carette et al. (1993), Casuccio et al. (2008), Demir (2009), Dilbas et al. (2014), Dossey et al. (1994), Etxeberria et al. (2007a-b), Evangelista (2014), Evangelista and de Brito (2017), Gomez-Soberon (2002), GonzálezFonteboa and Martínez-Abella (2004, 2005), González-Fonteboa et al. (2011), Gutierrez and Canovas (1995), Hamad and Dawi (2017), Kheder and Al-Windaw (2005), Kliszczewicz and Ajdukiewicz (2002), Koulouris et al. (2004), Naik et al. (1998), Omary et al. (2018), Paul (2011), Pedro et al. (2014), Piasta et al. (2017), Pul (2008), Remesar et al. (2017), Sadati and Khayat (2016), Sivasundaram et al. (1989, 1991), Tufail et al. (2017), Zega and Di Maio (2006, 2009);

- $\phi 100 \mathrm{~mm}$ cylinders: Aitcin and Mehta (1990), Akcay et al. (2012), Aksut and Yetgin (2017), Arezoumandi et al. (2015a-b), Bordelon et al. (2009), Butler (2012), Butler et al. (2013), Cetin and Carrasquillo (1998), Chang et al. (2001), Choi et al. (2012), Cülfik and Özturan (2010), Donza et al. (2002), Freyne et al. (2004), Gholampour and Ozbakkaloglu (2017), Giaccio and Zerbino (1998), Gonzalez-Corominas and Etxeberria (2014), Gonzalez-Corominas et al. (2017), Huang et al. (2013), Huda and Alam (2014), Iravani (1996), Jin and Li (2003), Khaliq and Taimur (2018), Kim et al. (2002), Kou et al. (2007), Lee and Yoon (2015), Manzi et al. (2013), Mesbah et al. (2002), Ozbakkaloglu et al. (2018), Park et al. (2013), Pepe (2015), Razaquur et al. (2010), Sadati and Khayat (2016), Tasdemir and Karihaloo (2001), Teranishi et al. (1998), Tibbetts et al. (2018), Vogel and Svecova (2012), Yanagi et al. (1998), Yang et al. (2008), Yiğiter et al. (2007), Yoshitake et al. (2014).

The sources of the $f_{c} v s$. $f_{c t}$ data were:

- $\phi 150 \mathrm{~mm}$ cylinders: Ajdukiewicz and Kliszczewicz (2002, 2007), Alonso et al. (2002), Ashour (2000), Bakhsh et al. (1990), Bravo et al. (2015a), Demir (2009), Dossey et al. (1994), Etxeberria et al. (2007a-b), Evangelista (2014), Evangelista and de Brito (2017), Oluokun et al. (1991), Gardner (1990), Gardner et al. (1988), Gerges et al. (2015), Giaccio and Zerbino (1998), GomezSoberon (2002), González-Fonteboa and Martínez-Abella (2004, 2005), GonzálezFonteboa et al. (2011), Gupta et al. (2016), Hamad and Dawi (2017), Kliszczewicz and Ajdukiewicz (2002), Muhammad and Sankaranarayanan (2016), Naik et al. (1998), Omary et al. (2018), Pedro et al. (2014), Proske et al. (2014), Pul (2008), Sadati and Khayat (2016), Saouma et al. (1991), Sivasundaram et al. (1989), Tufail et al. (2017), Yagishita et al. (1993), Zega and Di Maio (2011);

- $\quad$ 100 mm cylinders: Adams et al. (2016), Aksut and Yetgin (2017), Amario et al. (2017), Andal et al. (2016), Arezoumandi et al. (2014, 2015a-b), Bordelon et al. (2009), Butler (2012), Butler et al. (2013), Chang et al. (2001), Cülfik and Özturan (2010), Durán-Herrera et al. (2011), Becker and Javier (2018), Freyne et al. (2004), Gholampour and Ozbakkaloglu (2017, 2018), Giaccio and Zerbino (1998), Gonzalez-Corominas and Etxeberria (2014), Gonzalez-Corominas et al. (2017), Kang et al. (2014), Khaliq and Taimur (2018), Khan-
$\Phi 150 \times 300$ cylinders

- Basalt (BS)

- Granite (GR)

- Limestone (LS)

- Sandstone (SS)

- Quartzite (QZ)

- Recycled concrete aggregate (RA)

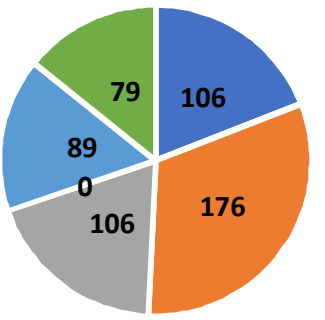

Fig. 1 Number of mixes of each aggregate type $-\theta_{E}$ database.

$\Phi 150 \times 300$ cylinders

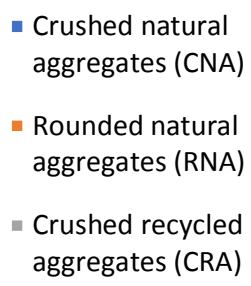

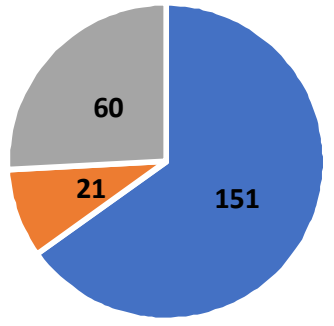

$\Phi 100 \times 200$ cylinders

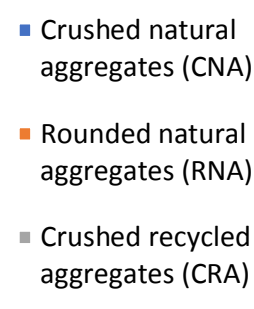

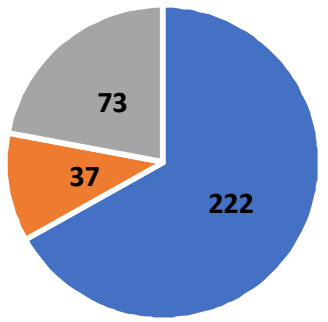

Fig. 2 Number of mixes of each aggregate morphology - $\theta_{f c t}$ database. 
zadi and Behnood (2009), Kim et al. (2002, 2013, 2016), Kou and Poon (2015), Kou et al. (2007), Lam et al. (1998), Laneyrie et al. (2016), Lee and Yoon (2015), Lotfy and Al-Fayez (2015), Manzi et al. (2013), Mohammed et al. (2017), Mouret et al. (1997), Naik et al. (2011), Park et al. (2013), Pepe (2015), Sadati and Khayat (2016), Soleymani Ashtiani et al. (2013), Tangchirapat et al. (2013), Uzal et al. (2007), Yang et al. (2008), Yiğiter et al. (2007), Yildirim et al. (2015), Yoshitake et al. $(2013,2014)$.

Most of the data concern crushed LS. This was expected due to the representativity of LS aggregates in the concrete industry. The analysis of the $f_{c} v s . f_{c t}$ relationship of RNA was limited by the reduced number of studies and mixes found.

The datasets divided by $f_{c}$ range are detailed in the tables of the Appendix. The number of mixes and the main statistical descriptors of each dataset are also shown there. The tables of the Appendix show the maximum percentage of mixes from each population that were sourced from the same investigation. Datasets that are excessively dependent on a particular investigation are not ideal since the $\theta$ models will be dependent on the particular mix design, materials, and equipment used in that research. This was considered during the analysis of the results.

$E$ subpopulations with SS aggregates were studied for $\phi 100 \mathrm{~mm}$ cylinders only due to scarce data on $\phi$ $150 \mathrm{~mm}$ cylinders. For the same reason, QZ aggregate concrete was analysed for $\phi 150 \mathrm{~mm}$ specimens only.

\section{Young's modulus}

\subsection{General analysis of trends and code accu- racy}

Figure 3 shows the $f_{c} v s . E_{c}$ scatterplots of all concrete produced with all aggregate types and both cylinder sizes.

Some trends are reported:

1. The relationship of ACI 318 differs from that of the other codes, especially in the low strength range;

2. The relationships of Model Code 2010 and Eurocode 2 (2020) are practically the same;

3. The $\theta_{E}$ of all standards is dependent on aggregate type. The $\alpha$ factor used in both Eurocode versions and Model Code 2010 does not reduce the influence of aggregate type on $\theta_{E}$;

4. From these data, the $\alpha$ factor of concrete with GR seems too high and the $\alpha$ factor of LS aggregates too low;

5. The $\theta_{E}$ of $\phi 100 \mathrm{~mm}$ cylinders and of $\phi 150 \mathrm{~mm}$ cylinders are similarly scattered;

6. The $E_{c}$ of RA concrete is underestimated by both Eurocode versions and Model Code 2010 when an $\alpha$ factor of 0.7 is used. However, since RA concrete is a new structural material with few full-scale applications (Pacheco et al. 2015), underestimating its prop- erties until proven applications by the construction industry is usually a cautious option.

The datasets of the different types of aggregates differ in mix design, binder blends and $f_{c}$, since the data appraised came from several institutions and regions. A fair comparison between types of aggregate requires an analysis by strength intervals, as well as the consideration of the binder blends used. The next section of the paper deals with this aspect.

Since the analysis of the $f_{c}$ vs. $E_{c}$ models of Eurocode 2 (2008), Eurocode 2 (2020), and Model Code 2010 is quite similar, the discussion will mostly focus on Eurocode 2 (2008) and ACI 318. The same option was made when presenting the analysis of $f_{c} v s . f_{c t}$. The Appendix has the results of all codes.

\subsection{Analysis by datasets}

Figure 4 plots the $\theta_{E}$ of GR and RA concrete when Eurocode 2 (2008) relationships are used. The percentage of cement replacement with other materials and the cylinder size of the data are also provided.

It is clear that different strength intervals are biased towards particular binder blends (for instance OPC for lower strength ranges and SF for high-strength concrete). This means that the influence of binder blends and $f_{c}$ on $\theta_{E}$ cannot be analysed separately. The $\theta_{E}$ analyses are made by checking the specific statistics of each strength interval and type of aggregate and assuming that the mix designs of the data appraised are representative of concrete of that strength interval. When unexpected trends were found, the particular mix designs of those datasets are analysed.

The statistics analysed were the average and coefficient of variation $(\mathrm{CoV})$ of $\theta_{E}$ since the sample standard deviation was found to be more dependent on $f_{c}$ than the CoV. The Appendix presents the standard deviation, as well as the skewness and kurtosis of each dataset.

Figure 5 shows the average and $\mathrm{CoV}$ of $\theta_{E}$ off all aggregate types calculated using the relationship of Eurocode 2 (2008).

Some trends are found:

1 . In most cases, the average $\theta_{E}$ of $\phi 150 \mathrm{~mm}$ cylinders is higher than the $\theta_{E}$ of $\phi 100 \mathrm{~mm}$ cylinders. This is explained by the physical phenomena behind statistical and fracture mechanics size effects (Bažant and Yavari 2005): $f_{c}$ tends to decrease with increases in specimen size both due to:

- Increased probability of finding weak zones in materials (statistical size effects);

- For the same stress, the elastic energy stored in a specimen increases with its size. On the other hand, failure develops in a region that is almost independent on the specimen size (fracture mechanics size effects), i.e. the elastic energy released after cracking is higher in larger specimens. When $E_{c}$ is tested, fracture mechanics' size effects are not as relevant, since the stresses on the specimen 
are well below $f_{c}$, therefore cracking is limited. Moreover, in $E_{c}$ tests the average strain of a significant portion of the specimen is measured, so the effect of weak regions is averaged out and statistical size effects are reduced. Since $f_{c}$ increases for smaller specimens but $E_{c}$ is negligibly affected, codified $f_{c}$ vs. $E_{c}$ relationships developed from tests on $\phi 100 \mathrm{~mm}$ cylinders will underestimate $E_{c}$ in comparison to relationships developed from tests on the standard cylinder size;

2. Cylinder size did not have a meaningful effect on the $\mathrm{CoV}$ of $\theta_{E}$. By analyzing the sample sizes and the
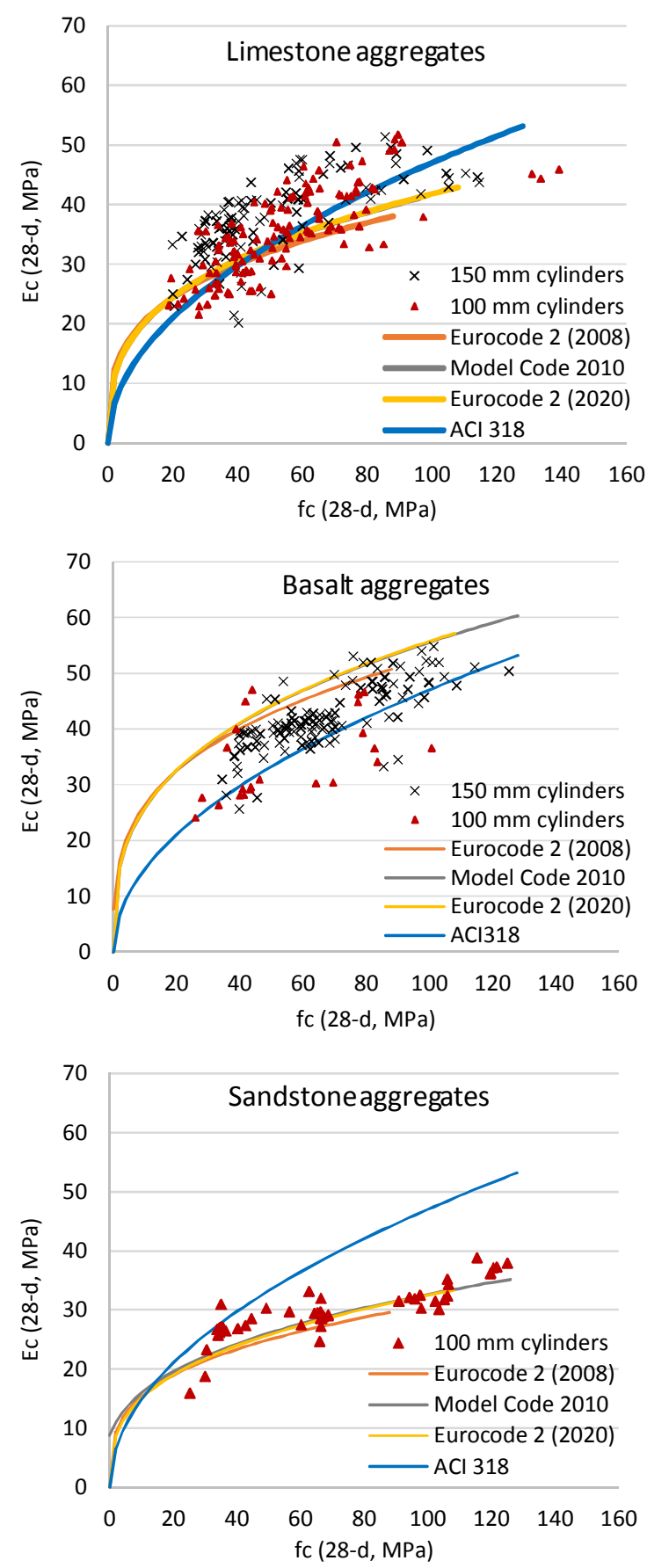

maximum percentage of mixes coming from the same paper (Appendix), as well as the particular mix designs of each set of data, it becomes clear that a scientifically-sound prediction of the variability of $\theta_{E}$ cannot be made. Nevertheless, a $\mathrm{CoV}$ of $12 \%$ suits the data well enough for SLS reliability purposes, as will be shown in section 4.4;

3. The $\alpha$ factor used in Equations (5) - (7) does not ensure similar code accuracy between aggregate types. For instance, the $E_{c}$ of concrete with either LS or RA is underestimated by all codes except ACI 318. The reduction of the $E_{c}$ of LS concrete in Eurocode
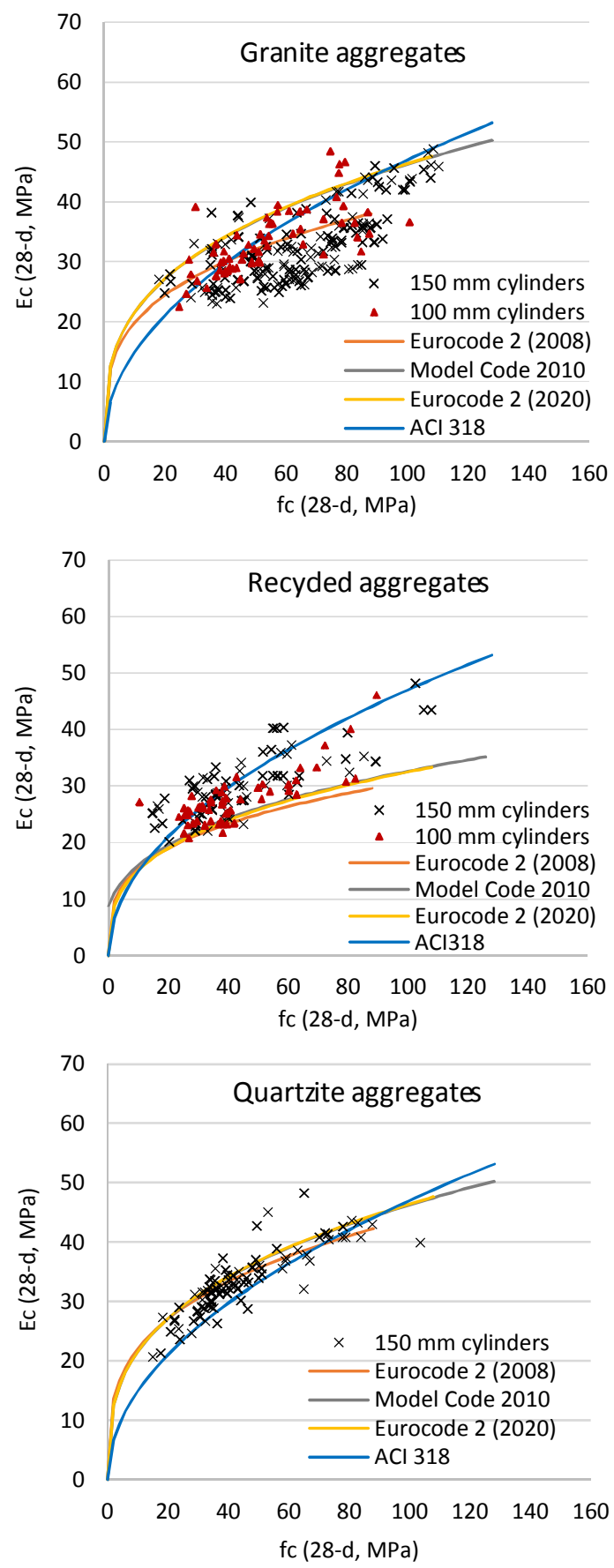

Fig. $3 f_{c}$ vs. $E_{c}$ relationships. 
2 (2008), Eurocode 2 (2020), and Model Code 2010 is not consensual. Noguchi et al. (2009) compiled data from several authors and found that LS concrete tends to have higher $E_{c}$ than $\mathrm{QZ}$ and BS concrete. These contradictory findings in comparison to Eurocode 2 and Model Code 2010 must be related both with differences in the properties of stones coming from quarries of different regions and with the specific mix design and specimen geometries of the mixes tested in each investigation;

4. The $f_{c}$ vs. $E_{c}$ relationship of ACI 318 does not account for the type of aggregate but its $\theta_{E}$ is as dependent on the aggregate type as the $\theta_{E}$ of the other documents. This follows from the previous conclusion: even though Equations (5) - (7) use the $\alpha$ factor, a homogenous $\theta_{E}$ between aggregate types is not achieved. This finding has important consequences on the reliability of SLS that depend on concrete stiffness.

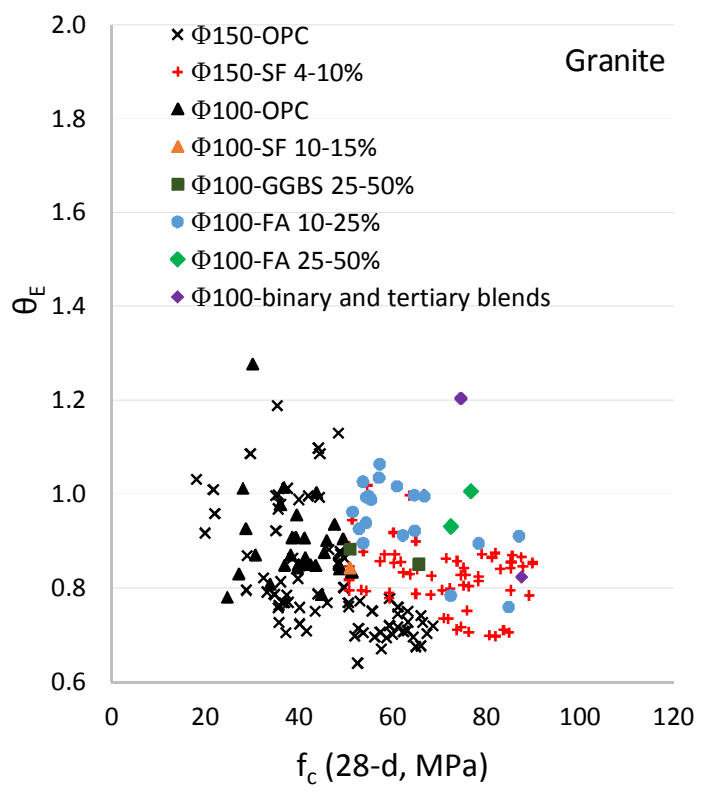

Some populations did not conform with the trends reported above. When specific datasets are analysed, reasons for such divergences are found. The average $\theta_{E}$ of GR concrete of $\phi 100 \mathrm{~mm}$ cylinders is higher than the average $\theta_{E}$ of $\phi 150 \mathrm{~mm}$ cylinders, especially in the 50 - $90 \mathrm{MPa} f_{c}$ range. This is explained by the particular admixtures used and the age of testing (28 days). Figure 4 shows that for $f_{c}$ above $50 \mathrm{MPa}$ :

- The $\phi 100 \mathrm{~mm}$ data of GR concrete concern mostly concrete with $10 \%$ to $25 \%$ of FA by total binder weight;

- The $\phi 100 \mathrm{~mm}$ data concern concrete with either OPC or OPC with $4 \%$ to $10 \%$ of SF;

All data come from specimens tested at the conventional age of 28 days. However, the pozzolanic reactions of FA are only noticeable several weeks after the onset of hydration (Langan 2002). At 28-days, the ITZ improvements caused by FA incorporation are not relevant and FA acts mostly as a filler, reducing porosity but hav-

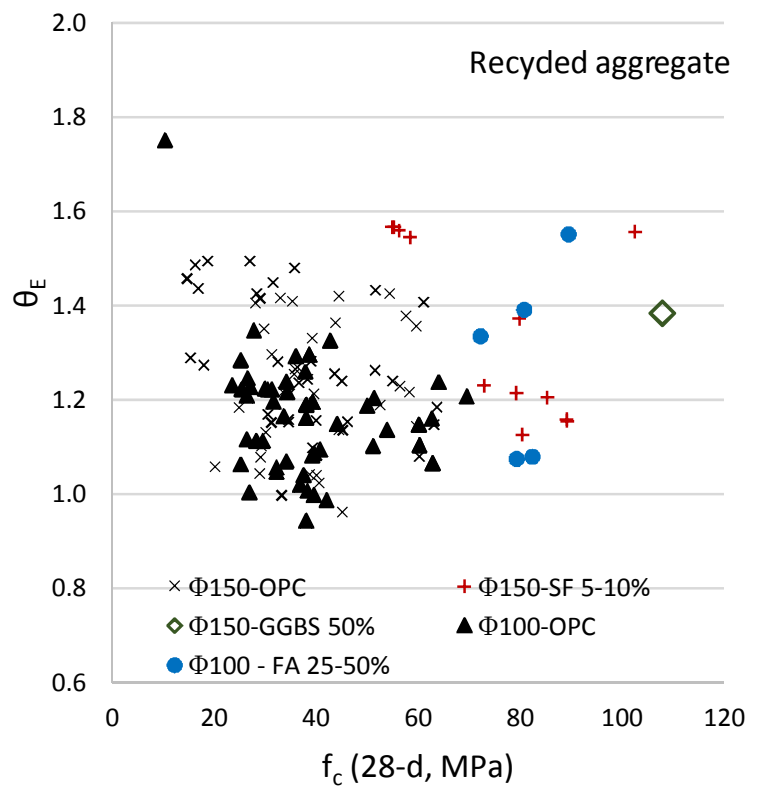

Fig. $4 f_{c m}$ vs. $\theta_{E}$ scatterplot of GR and RA concrete. Eurocode 2 (2008).

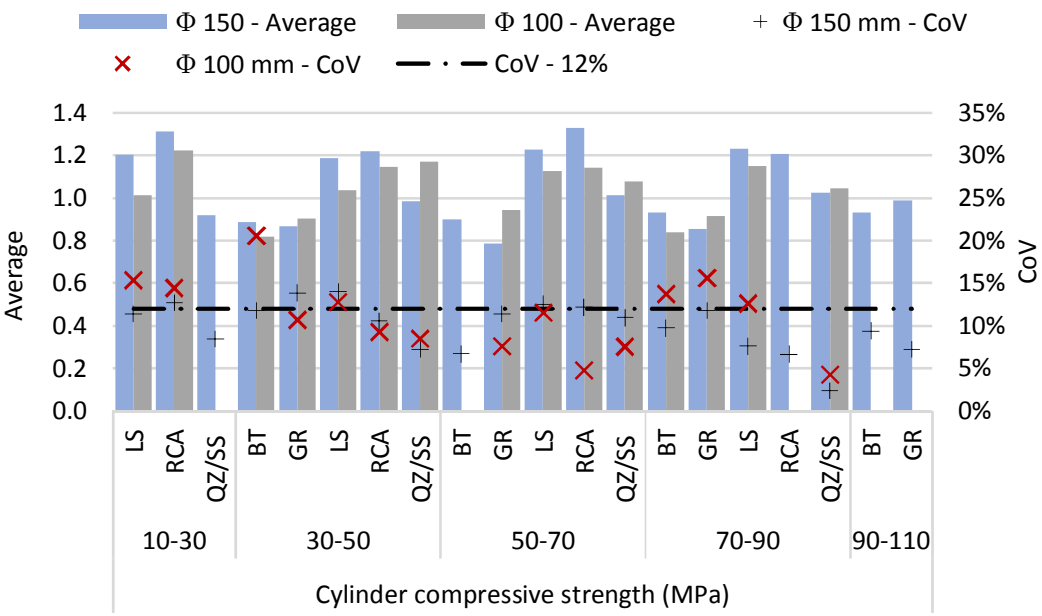

Fig. 5 Average and CoV of $\theta_{E}$ for each population. Eurocode 2 (2008). 
Table 2 Average $\theta_{E}$ of the probabilistic models.

\begin{tabular}{|c|c|c|c|c|c|}
\hline & \multicolumn{3}{|c|}{ Average $\theta_{E}$ for $\Phi 150 \mathrm{~mm}$} & CoV & $\Phi 100 / \Phi 150$ \\
\hline Aggregate & Eurocode 2 (2008) & MC 2010 and Eurocode 2 (2020) & ACI 318 & All codes & All codes \\
\hline LS & 1.20 & 1.15 & 1.15 & $12 \%$ & 0.90 \\
\hline QZ & 1.00 & 0.95 & 1.05 & $12 \%$ & - \\
\hline BS & 0.90 & 0.90 & 1.10 & $12 \%$ & - \\
\hline GR & 0.85 & 0.80 & 0.85 & $12 \%$ & $0.90(1.05)^{*}$ \\
\hline RA & 1.20 & 1.20 & $12 \%$ & 0.95 \\
\hline
\end{tabular}

* The actual value is 1.05 but 0.90 is recommended conservatively (the specific binder blends of GR concrete may have conditioned its analysis)

ing little influence in crack arrest. This means that at 28 days FA will contribute more to $E_{c}$ than to $f_{c}$, since $E_{c}$ is tested under reduced stresses $\left(30 \%\right.$ to $40 \%$ of $\left.f_{c}\right)$ and crack propagation is not significant. Differerent authors have reported that concrete with FA has higher $f_{c}$ gains over time in comparison to $E_{c}$ (Marques et al. 2013, Pacheco et al. 2019a, Siddique 2004).

Relevant increases in $\theta_{E}$ when SF is used are not observed. SF is a highly reactive admixture and provides a significant amount of calcium silicate hydrates from the onset of hydration, contributing to early-age strength development (Langan 2002).

Noguchi et al. (2009) have also reported that FA incorporation skews the $f_{c}$ vs. $E_{c}$ relationships towards higher values of $E_{c}$, while SF does not have that effect.

\subsection{Goodness-of-fit testing}

All subpopulations were checked for lognormal and normal distribution fits. Figure 6 plots the distributions of the subpopulations with compressive strength between 30 and $50 \mathrm{MPa}, \phi 150 \mathrm{~mm}$ cylinders, and with two types of coarse aggregates: RA (left) and LS (right).

Most of the distributions were suitably modelled by both normal and lognormal distributions. Some distributions could not be suitably modelled by either, but the purpose of these distributions (probabilistic models for SLS), allows normal and/or lognormal distributions:

- SLS have relatively high acceptable probabilities of failure: ISO2394 (1998) recommends probabilities of failure of about $7 \%$ for irreversible SLS and $50 \%$ for reversible SLS);

- The $\theta_{E}$ of constitutive models is one of the many

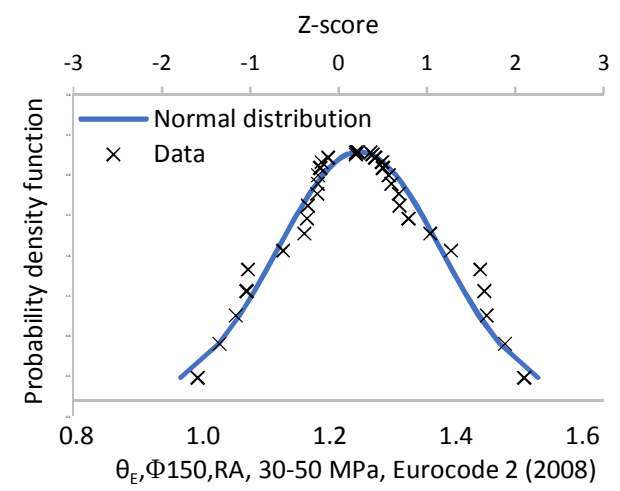

resistance variables involved in the reliability of SLS. Assuming that $\theta$ is not the most relevant resistance variable (a fair assumption since the reliability of concrete elements under deformability verifications is expected to be more dependent on the statistics of the geometric parameters related to the inertia of cross-sections), $\theta_{E d}$ is expected to be close to the average $\theta_{E}$. From this follows that probability models with ill-fitted tails (Fig. 6, right) are not necessarily unsuitable within scope of SLS reliability analyses. This will be developed in the next section.

\subsection{Proposed model for $\theta_{E}$}

The probabilistic conversion model from code-predicted to actual $E_{c}$ is defined by:

$$
E_{c, \text { actual }}=\theta_{E} \times E_{c, \text { code }}
$$

where $\theta_{E}$ is normally distributed with a $\mathrm{CoV}$ of $12 \%$ and the expected values are shown in Table 2.

This conversion is intended for $\phi 150 \mathrm{~mm}$ cylinders. If $f_{c}$ tests on $\phi 100 \mathrm{~mm}$ cylinders are used, the expected value of $\theta_{E}$ should be multiplied by the ratio given in the same table. The $\mathrm{CoV}$ is independent of the cylinder size. Ratios for BS concrete were not developed due to insufficient sampling.

The expected value of $\theta_{E}$ of each aggregate type was defined by calculating the weighted average of the average $\theta_{E}$ of each strength range. This weighted average gave mixes within the $30-50 \mathrm{MPa}$ and $50-70 \mathrm{MPa}$ strength ranges three times more relevance in comparison to mixes of the respective $10-30 \mathrm{MPa}, 70-90 \mathrm{MPa}$, and $90-110 \mathrm{MPa}$ datasets (Fig. 5 and the Appendix

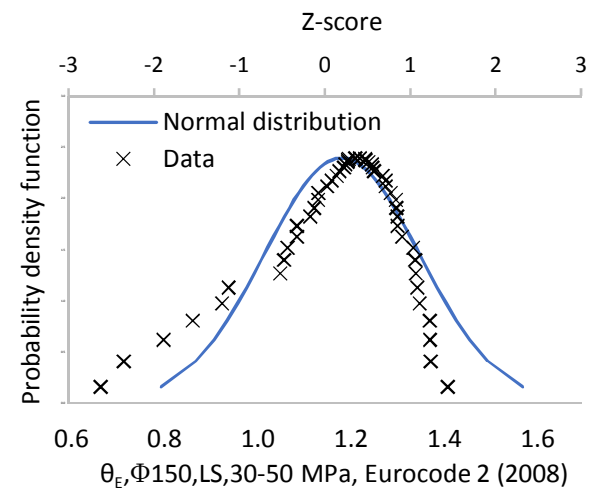

Fig. $6 \theta_{E}$ normal distribution goodness-of-fit testing. Left): properly fitted data, right): unproperly fitted data but acceptable model. 
Table 3 Estimated $\theta_{E d}$. Design service life of 50 years and a $\beta$ of 1.5 .

\begin{tabular}{|c|c|c|c|}
\hline Aggregate & Eurocode 2 (2008) & MC 2010 and Eurocode 2 (2020) & ACI 318 \\
\hline LS & 1.03 & 0.98 & 0.98 \\
\hline QZ & 0.86 & 0.81 & 0.90 \\
\hline BS & 0.77 & 0.77 & 0.94 \\
\hline GR & 0.73 & 0.68 & 0.73 \\
\hline RA & 1.03 & 1.03 & 0.77 \\
\hline
\end{tabular}

show the averages of all datasets).

The $\phi 100 / \phi 150$ ratio of GR concrete was higher than 1.0, a finding that lacks physical validity and was probably due to the specific mix design of the $\phi 100$ mm cylinder GR mixes, as stated previously.

The same CoV (12\%) is recommended for both cylinders' sizes and all types of aggregates of all codes since it suitably represents the $\mathrm{CoV}$ of most populations analysed. Cases that deviate significantly from the proposed $\mathrm{CoV}$ were analysed and correspond to populations that were mostly dependent on a single research.

The suitability of the models proposed in Table 2 was checked by comparing the preliminary design $\left(\theta_{E d}\right)$ values of the $\theta_{E}$ models with the preliminary $\theta_{E d}$ calculated from each individual dataset. These preliminary $\theta_{E d}$ were estimated using the clauses of Annex $\mathrm{C}$ of Eurocode 0 (2002), as shown in Equation (10):

$$
\theta_{E d}=\text { Average }\left(\theta_{E}\right)-\alpha_{R, F O R M} \times \beta \times C o V \times \text { Average }\left(\theta_{E}\right)(10)
$$

where:

- $\beta$ is the target reliability index recommended for irreversible SLS over a design service life of 50 years ( $\beta=1.5$, corresponding to a probability of failure of $7 \%)$

- $\alpha_{R, F O R M}$ is a conservative estimate of the sensitivity factor of a reliability analysis based on a first order reliability method (Madsen et al. 1986). Eurocode 0 recommends $\alpha_{R, F O R M}=0.8$ for leading resistance variables.

Equation (10) assumes $\theta_{E}$ as normally distributed. Considering $\alpha_{F O R M}=0.8$ is an overestimation of the effect of $\theta_{E}$ on reliability, since $\theta_{E}$ is not expected to be a leading resistance variable. Lower $\alpha_{R, F O R M}$ values would result in $\theta_{E d}$ closer to the average $\theta_{E}$.

Table 3 shows the $\theta_{E d}$ values obtained using the proposed models.
Figure 7 shows the Eurocode 2 (2020) and ACI 318 relative errors $\left(\Delta_{r e l}\right)$ of the $\theta_{E d}$ calculated with the proposed models and those of the datasets (assuming a normal distribution). Values above zero are conservative (underestimates of $E_{c}$ ). Model Code 2010 and Eurocode 2 (2020) statistics are fairly close to those of Eurocode 2 and can be observed in Tables A.1 and A.2 of the Appendix. The absolute errors $\left(\Delta_{a b s}\right)$ are also in in Tables A.1 and A.2.

Most of the errors of the models are conservative and the absolute value of $\Delta_{r e l}$ is lower than $10 \%$ in almost all cases.

\section{Tensile strength}

\subsection{General analysis of trends and code accu- racy}

The $f_{c}$ vs. $f_{c t}$ relationships of Eurocode 2 (2008) and ACI 318 are plotted in Figs. 8 - 10. Model Code 2010 and Eurocode 2 (2020) relationships are virtually the same as those of Eurocode 2 (2008). The 5\% and 95\% characteristic $f_{c t k}$ estimates of Eurocode 2 (2008) are also plotted.

Figure 8 shows that the CNA concrete data are representative in all strength ranges. From Fig. 9 it is concluded that data on RNA are lacking and Fig. 10 shows that data on CRA concrete adequately cover the common strength classes.

Almost all data in the common strength classes of all aggregate morphologies concern concrete with plain OPC blends. High-strength concrete with CRA was made with either SF (3-10\% of cement replacement) or FA $(25-50 \%)$. Several binder blends were used in the high-strength concrete produced with CNA. The few RNA concrete mixes with high $f_{c}$ were produced mainly with FA (25 - 50\% of cement replacement).

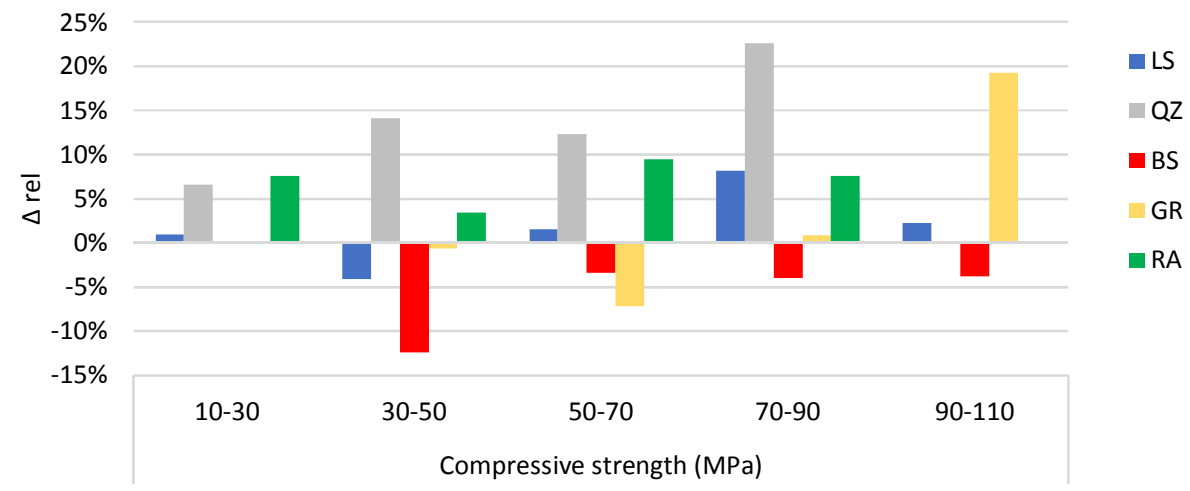

Fig. 7 Relative errors of $\theta_{E d}$ when the proposed probability models are used. 


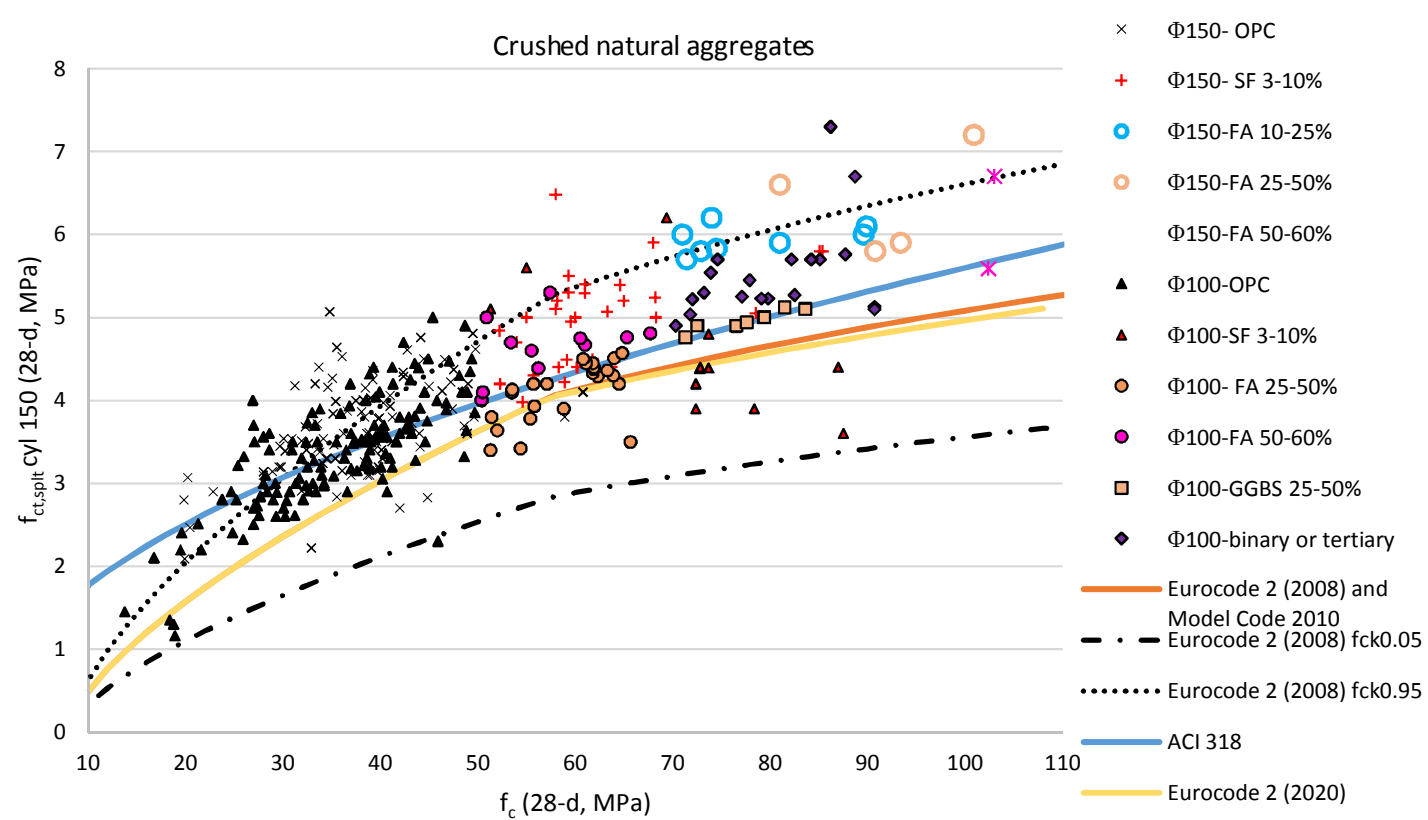

Fig. $8 f_{c}$ vs. $f_{c t}$ relationships: CAN.

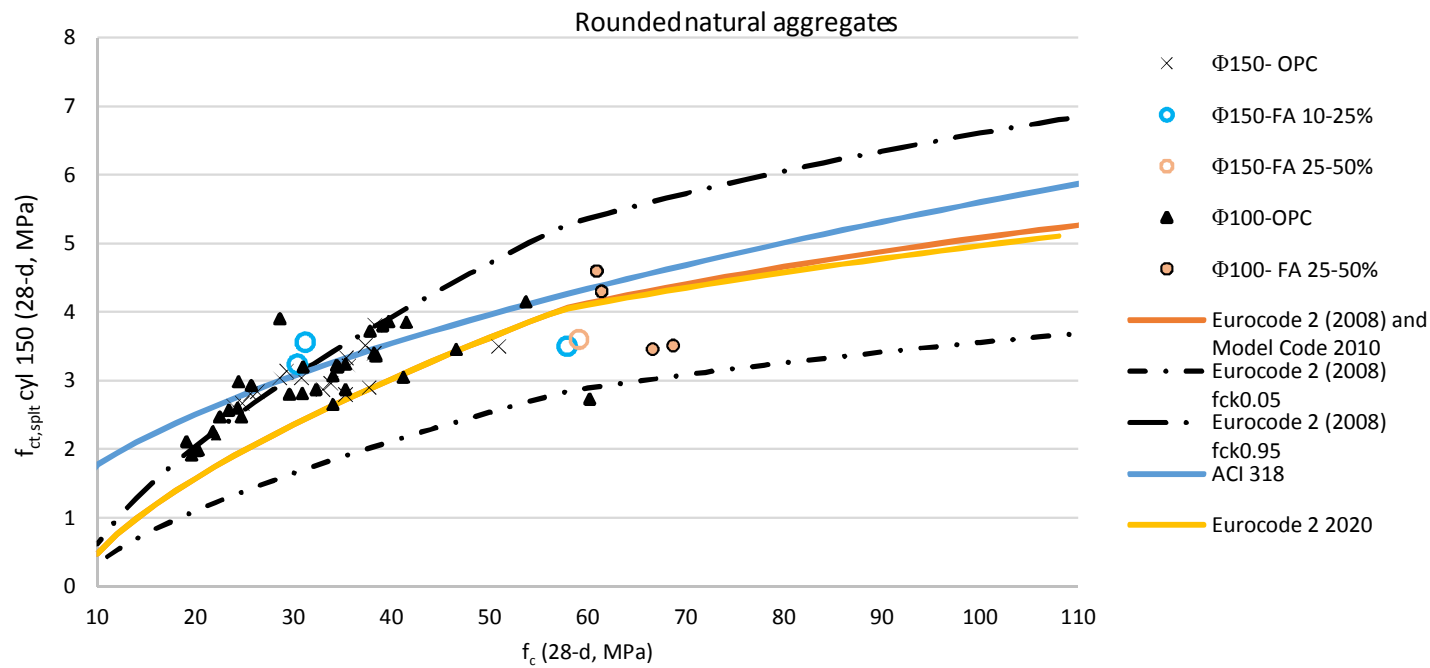

Fig. $9 f_{c}$ vs. $f_{c t}$ relationships: RNA.

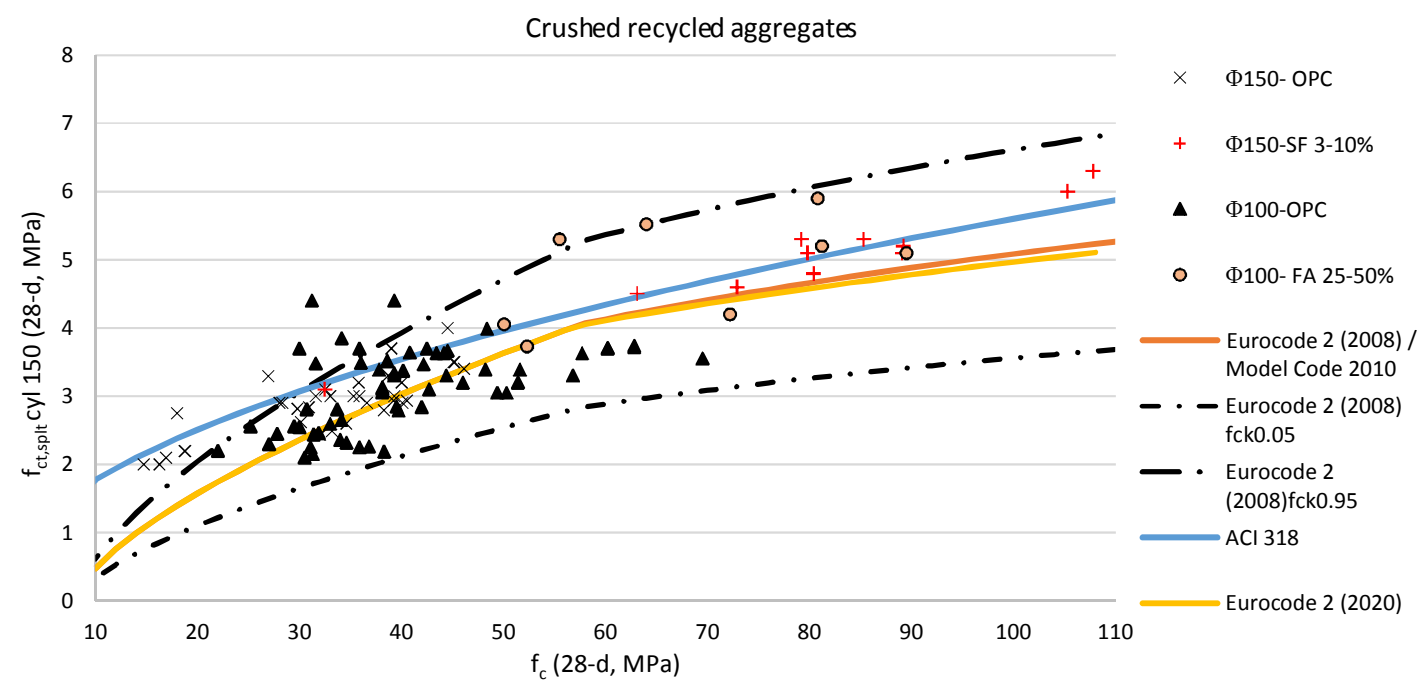

Fig. $10 f_{c}$ vs. $f_{c t}$ relationships: CRA. 
The following trends are observed:

1. Both versions of Eurocode 2 and Model Code 2010 predict almost the same $f_{c t}$. The predictions of ACI 318 are higher than all others;

2. Eurocode 2 and Model Code 2010 consistently underestimate the $f_{c t}$ of CNA, especially in the lower strength range. The $f_{c t}$ of RNA is also underestimated in the low to medium strength range;

3. The $f_{c t}$ of CRA concrete is below expectations when the relationship of ACI 318 is used and underestimated by Eurocode 2 and Model Code 2010 in more instances than when concrete is produced with the other aggregate morphologies;

4. Almost all data of the three aggregate morphologies are above the 5\% characteristic predictions of Eurocode 2 and Model Code 2010. The $f_{c t}$ of CNA is clearly underestimated: $37 \%$ of the $\phi 150 \mathrm{~mm}$ data and $21 \%$ of the $\phi 100 \mathrm{~mm}$ cylinder data are above the $95 \%$ fractile estimate of $f_{c t}$.

The above conclusions assume that the splitting tensile strength is equal to the uniaxial $f_{c t}$. Malárics and Muller (2010) recommended a conversion factor of 1.0 but found that, in fact, the conversion factor depends on $f_{c}$ and is greater than 1.0 for lower strength concrete. This justifies why most data above the prediction of the $95 \%$ fractile lie in the low to medium strength range.

\subsection{Analysis of datasets}

Figure 11 shows the average and $\mathrm{CoV}$ of $\theta_{f c t}$ calculated using the Eurocode 2 (2008) and ACI 318 relationships. The $\theta_{f c t}$ of the other documents are similar to that of Eurocode 2 (2008).

There is a slight trend towards $\phi 150 \mathrm{~mm}$ cylinders having higher average $f_{c t}$ than $\phi 100 \mathrm{~mm}$ ones. This is because $f_{c t}$ is almost size independent when the test setup has narrow load-bearing strips - as common in standards (fib 2013); Rocco et al. 1999a, 1999b), and the size of the cylindrical specimen is common (including $\phi 150 \mathrm{~mm}$ and $\phi 100 \mathrm{~mm}$ ). Since $f_{c}$ is not size

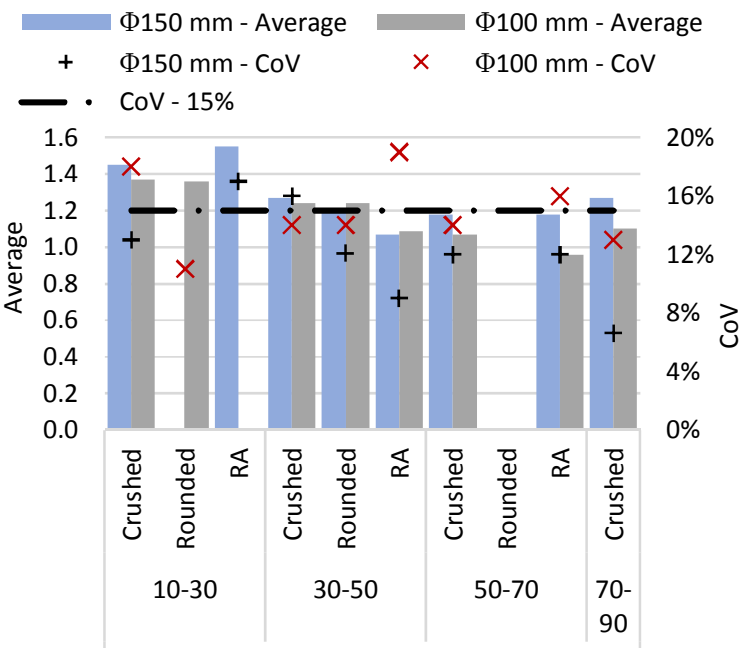

Cylinder compressive strength (MPa) independent, negligible $f_{c t}$ size effects result in $\phi 100$ mm cylinders having higher $f_{c}$ and similar $f_{c t}$ in comparison to the properties of standard cylinders. This means that $f_{c} v s$. $f_{c t}$ relationships developed from tests on $\phi 100 \mathrm{~mm}$ cylinders will underestimate $f_{c t}$ in comparison to the standard size of codes.

The reduced influence of specimen size on the $f_{c t}$ may seem unexpected, since uniaxial tensile failures are more brittle than compressive failures (fib 2013, van Mier and Mechtcherine 2007). However, the failure mechanism of splitting tensile strength tests is very different from the mechanism of uniaxial tensile strength tests, which are characterized by the development of a few bridging cracks without potential for crack arresting (Mehta and Monteiro 2006). As Malárics and Müller (2010) have shown, splitting tensile strength specimens are subjected to a complex multiaxial stress-state, with a crack pattern that is dependent on the specimen's geometry, material properties and even the width of the load-bearing strips (Rocco et al. 1999a, 1999b), instead of being under uniaxial tension. This hinders intuitive deductions on the effect of specimen size on $f_{c t}$.

Some other findings are taken from Fig. 11:

1. ACI 318 predictions are fairly more accurate than all others, because the ACI 318 relationship estimates the splitting tensile strength and not the uniaxial $f_{c t}$;

2. The average $\theta_{f c t}$ of ACI 318 is homogenous for the different strength ranges, whilst the average $\theta_{f c t}$ of the other documents decreases with $f_{c}$, which is probably due to the shift of the failure pattern towards trans-aggregate fractures. This is especially noticed when CRA are used, because CRA are weaker than natural aggregates (Guo et al. 2017);

3. The $\mathrm{CoV}$ from $\phi 100 \mathrm{~mm}$ data is more variable than that of $\phi 150 \mathrm{~mm}$;

4. Concrete with RNA or CRA has lower $\theta_{f c t}$ than CNA concrete. The $f_{c t}$ of RNA concrete is limited by a weak ITZ (Arioglu et al. 2016) and the $f_{c t}$ of CRA concrete is limited by aggregate strength (Casuccio et

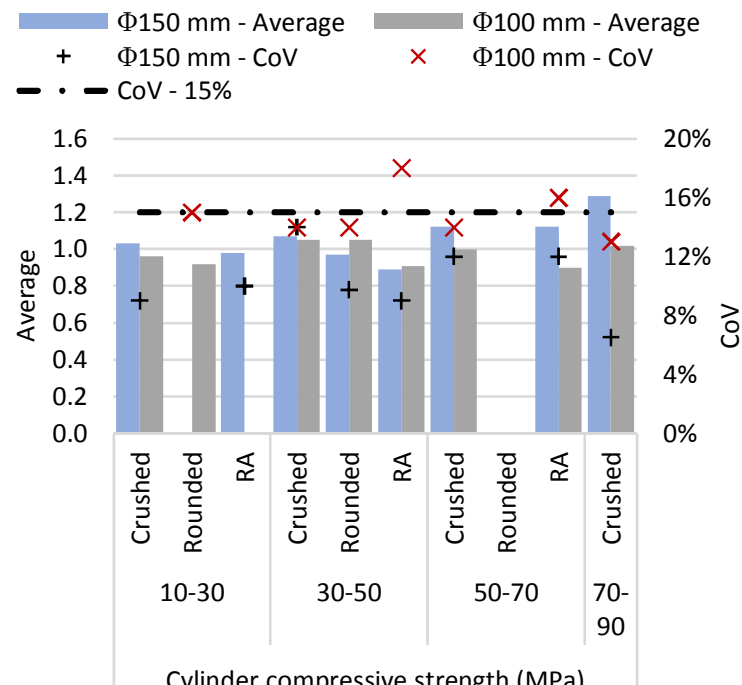

Cylinder compressive strength ( $\mathrm{MPa}$ )

Fig. 11 Average and CoV of $\theta_{f c t}$ for each population. Left: EC2 (2008); right: ACI 318. 
Table 4 Average of the probability models.

\begin{tabular}{|c|c|c|c|c|c|}
\cline { 2 - 6 } \multicolumn{1}{c|}{} & \multicolumn{2}{c|}{ Average $\theta_{\text {fct }}$ for $\phi 150 \mathrm{~mm}$} & CoV & \multicolumn{2}{c|}{$\phi 100 / \phi 150$} \\
\hline Aggregate morphology & $\begin{array}{c}\text { Eurocode 2 (2008) and (2020); } \\
\text { Model Code 2010 }\end{array}$ & ACI 318 & All codes & $\begin{array}{c}\text { Eurocode 2 (2008) and (2020); } \\
\text { Model Code 2010 }\end{array}$ & ACI 318 \\
\hline CNA & 1.25 & 1.15 & $15 \%$ & 0.90 & 0.90 \\
\hline CRA & 1.20 & 1.00 & $15 \%$ & 0.85 & 0.90 \\
\hline
\end{tabular}

\begin{tabular}{|c|c|c|c|c|c|c|}
\hline \multirow[b]{2}{*}{ Aggregate morphology } & \multicolumn{2}{|c|}{$\theta_{f c t d}$} & \multicolumn{2}{|c|}{$\theta_{\text {fctk } 0.05}$} & \multicolumn{2}{|c|}{$\theta_{\text {fctk } 0.95}$} \\
\hline & CNA & CRA & CNA & CRA & CNA & CRA \\
\hline Eurocode 2 (2008) and (2020), Model Code 2010 & 1.03 & 0.98 & 0.94 & 0.90 & 1.56 & 1.50 \\
\hline ACI 318 & 0.94 & 0.82 & - & - & - & - \\
\hline
\end{tabular}

\section{al. 2008);}

\subsection{Goodness-of-fit testing}

As seen for $\theta_{E}$, most distributions were suitably modelled by normal and lognormal distributions. Nevertheless, the use of these $\theta_{f c t}$ is restricted to SLS reliability analyses since some datasets were ill-fitted in the lower tail region. If $f_{c t}$ is a relevant parameter for ultimate limit states design, specific testing is recommended. Lognormal distributions fitted the data better than normal distributions in most instances (Fig. 12).

\subsection{Proposed model for $\theta_{f c t}$}

This section has a similar concept to section 4.4. Proposals are developed for CNA and CRA only, since data on RNA concrete are scarce and lack representativity. The conversion of the predicted to actual $f_{c t}$ is analogue to the $E_{c}$ conversion model:

$$
f_{c t, \text { actual }}=\theta_{f c t} \times f_{c t, c o d e}
$$

$\theta_{f c t}$ is normally distributed with a $\mathrm{CoV}$ of $15 \%$ and the expected values are shown in Table 4. Data were rounded to multiples of 0.05 . The same weighing function of the $\theta_{E}$ proposition was used.

A CoV of $15 \%$ conservatively estimates the variability of most populations of the four codes (Fig. 11). The suitability of this $\mathrm{CoV}$ in an SLS reliability framework

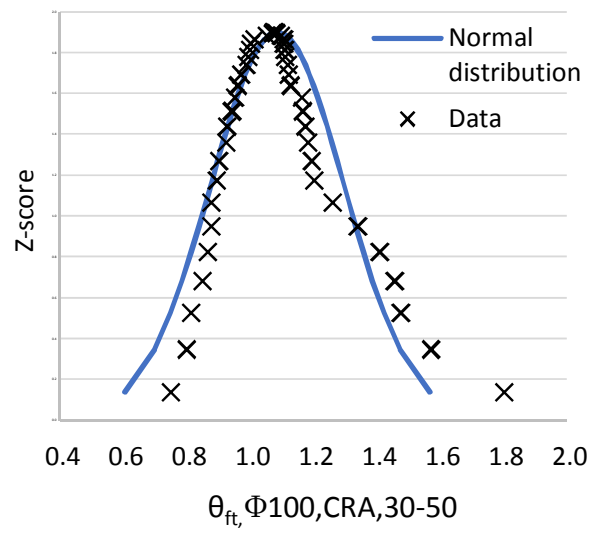

is assessed by comparing the design tensile strength ( $\theta_{f c t d}$ - calculated as shown in Equation (10) for $\theta_{E d}$ ) of the models proposed in Table 4 with the $\theta_{f c t d}$ of each dataset. The actual characteristic values of the $5 \%$ $\left(\theta_{\text {fctk } 0.05}\right)$ and 95\% $\left(\theta_{\text {fctk } 0.95}\right)$ fractiles of $f_{c t}$ were calculated for both Eurocode 2 versions and Model Code 2010. Table 5 shows the $\theta_{f c t d}, f_{c t k 0.05}$, and $f_{c t k 0.95}$ obtained. Despite a better fit of lognormal distributions to the data (Fig. 12) normal distributions were used in the calculations due to convenience as well as conservationism in the lower tail region (Gulvanessian et al. 2002), since the skewness of the datasets was positive in almost all instances.

Figure 13 shows the relative errors $\left(\Delta_{r e l}\right)$ between the $\theta_{\text {fctd }}$ calculated with the models of Table 4 and those of each dataset. The $\Delta_{\text {rel }}$ of Eurocode 2 (2020) and Model Code 2010 relationships are analogue to those of Eurocode 2 (2008) (Tables A.3 and A.4 of the Appendix). The absolute errors $\left(\Delta_{a b s}\right)$ are also shown in the Appendix.

The $\Delta_{r e l}$ of ACI 318 was negligible for $f_{c}$ below 70 $\mathrm{MPa}$. A relative error of $+20 \%$ was obtained for concrete in the 70 - $90 \mathrm{MPa}$ strength range, which was considered acceptable (positive $\Delta_{r e l}$ mean that the models proposed are conservative, and simplicity took precedence over developing a model with statistical descriptors that depended on $f_{c}$ ). The $\Delta_{r e l}$ of both Eurocode 2

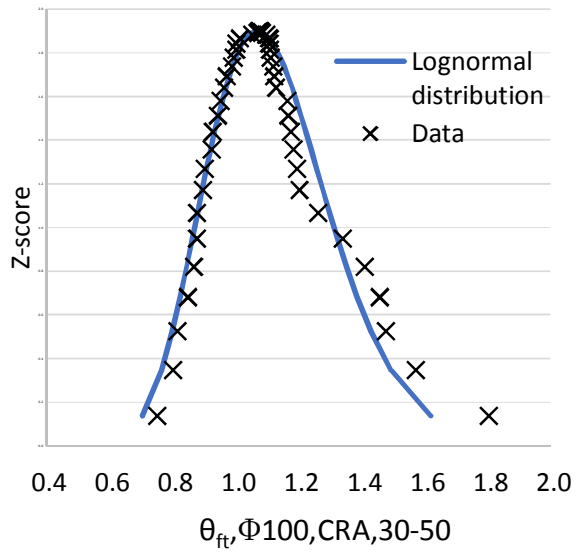

Fig. $12 \theta_{f c t}$ goodness-of-fit testing: left): normal distribution, right): lognormal distribution. 

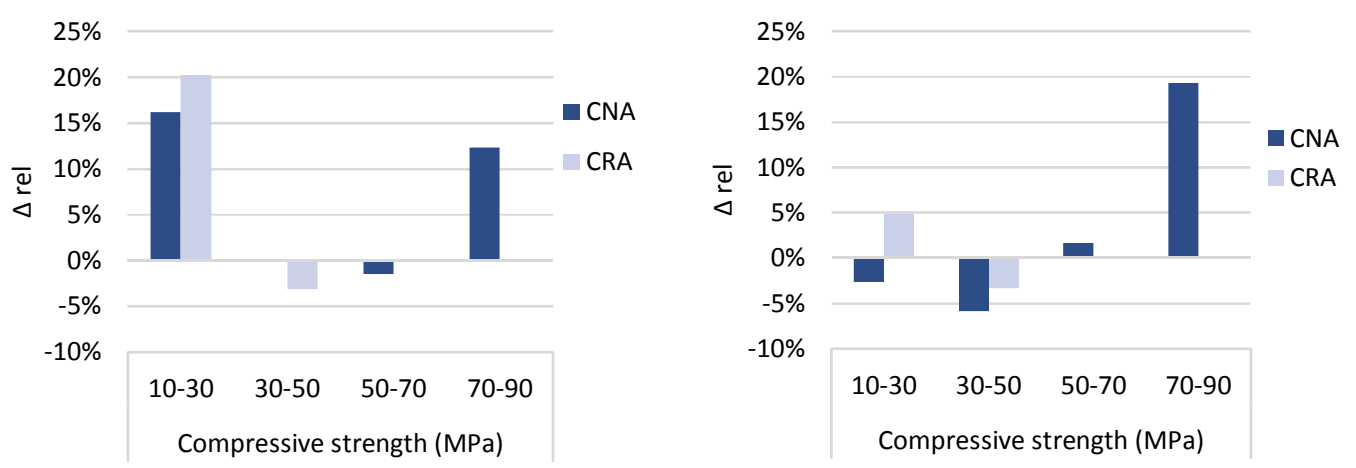

Fig. 13 Relative errors of $\theta_{f c t d}$ when the proposed probability models are used. Left: Eurocode 2 (2008); right: ACI 318.

versions and Model Code 2010 was negligible for concrete of common strength ranges (30 to $70 \mathrm{MPa})$ and overly conservative for concrete with $f_{c}$ between 10 $30 \mathrm{MPa}$ and $70-90 \mathrm{MPa}$. The reasoning for accepting the $\Delta_{r e l}$ of ACI 318 also holds.

By definition, both Eurocode versions and Model Code 2010 predict $f_{c t k 0.05}$ and $f_{c t k 0.95}$ as 0.7 and 1.3 times the code estimative of $f_{c t}$. The data from Table 5 show that both predictions are below experimental data of the splitting tensile strength. A full-scope study on the relationship between the uniaxial tensile strength and the splitting tensile strength should follow, in order to assess whether codes are in fact underestimating $f_{\text {ctk } 0.05}$ and $f_{c t k 0.95}$. Underestimations of $f_{\text {ctk } 0.95}$ are not conservative.

\section{Conclusions}

Current knowledge hinders reliability analyses on the serviceability limit-states of reinforced concrete structures, since the model uncertainties between code expectations and the actual tensile strength/Young's modulus have not been quantified probabilistically.

The importance of developing probabilistic models for these model uncertainties was discussed, as well as how the different mix designs and complex mechanisms of concrete behaviour hinder their assessment. Notwithstanding this fact, suitable models intended for SLS reliability assessment were developed for Eurocode 2, Model Code 2010 and ACI 318.

An extensive appraisal of 28-day test data coming from two specimens ( $\phi 150 \mathrm{~mm}$ cylinders, the standard specimen of codes, and $\phi 100 \mathrm{~mm}$ cylinders) was made and the data were separated in different datasets to limit the influence of mix design on the evaluation of the model uncertainty.

Concerning the codified constitutive modelling of Young's modulus:

- The $\alpha$ factors of Eurocode 2 and Model Code 2010 do not reduce the aggregate's influence on the accuracy of code predictions;

- The model uncertainty was fairly dependent on the lithological type of coarse aggregate used in the mix design. This finding has a significant influence on the reliability of limit states related to concrete stiffness;

- Normal and lognormal distributions suit the modelling uncertainty sufficiently well for serviceability limit states;

A probabilistic model uncertainty factor was proposed for concrete produced with four different types of coarse natural aggregate and for concrete made with coarse recycled concrete aggregates.

- Concerning the code predictions of the tensile strength:

The model uncertainty was evaluated for concrete produced with coarse crushed natural aggregates and for concrete with coarse crushed recycled aggregates;

- The tensile strength of concrete with crushed natural aggregates is significantly underestimated by codes. ACI 318 predicted the splitting tensile strength better than the other documents but overestimates the tensile strength when recycled aggregates are used;

- The Eurocode predictions of the characteristic tensile strength seem considerable underestimations of the actual data;

- The model uncertainty of the Eurocode 2 and Model Code 2010 relationships depends on the compressive strength, which will affect the reliability of designs;

A probabilistic model uncertainty factor was proposed for crushed natural and crushed recycled aggregate concrete. If the compressive strength is higher than $70 \mathrm{MPa}$ the splitting tensile strength should be tested;

- The tensile strength is commonly evaluated through splitting tests whilst Eurocode 2 and Model Code 2010 define the constitutive relationship in terms of the uniaxial tensile strength. If future probability models that convert splitting tensile strength data to uniaxial tensile strength are developed, they can be readily added to the model uncertainty proposed in this paper.

Notwithstanding the perceived notion that recycled concrete aggregates will result in concrete with uncertain behaviour, it was found that the scatter of the constitutive relationships of codes is similar to that of natural aggregates. Nevertheless, different model uncertainties should be used for different aggregate types (whether recycled or natural). Otherwise, reliability assessments are hindered by the unaccounted-for influ- 
ence of the aggregates on the model uncertainty.

The tails of the probability distributions did not suitably represent the extreme values of the data. The models proposed in this paper should be used on reliability analyses on serviceability limit states only. Specific tests on Young's modulus and tensile strength are recommended whenever either of the properties is relevant for ultimate limit state design.

If constitutive relationships are analysed based on tests on $\phi 100$ cylinders, Young's modulus and tensile strength predictions will be more conservative than if $\phi$ 150 cylinders are used. Conversion factors that reduce this effect were proposed.

Future research in this area should focus on the influence of aggregate types and morphologies on the actual reliability of concrete structures using the probability models proposed in this paper. The binder blends and strength ranges evaluated should be complemented by more experimental data. The model uncertainties of self-compacting concrete should also be assessed since they may differ from those studied in this paper.

\section{Acknowledgements}

The support of IST - University of Lisbon, the CERIS/ICIST research centre, and the EcoCoRe doctoral programme - grant PD/BD/113643/2015 of the Portuguese Foundation for Science and Technology (FCT), is gratefully acknowledged.

\section{References}

ACI318, (2014). "Building code requirements for structural concrete (ACI 318-14) and commentary." Michigan, USA: the American Concrete Institute.

Adams, M. P., Fu, T., Cabrera, A. G., Morales, M., Ideker, J. H. and Isgor, O. B., (2016). "Cracking susceptibility of concrete made with coarse recycled concrete aggregates." Construction and Building Materials, 102(1), 802-810.

Aitcin, P. C. and Mehta, P. K., (1990). "Effect of coarse aggregate characteristics on mechanical properties of high-strength concrete." Materials Journal, 87(2), 103-107.

Ajdukiewicz, A. and Kliszczewicz, A., (2002). "Influence of recycled aggregates on mechanical properties of HS/HPC." Cement and Concrete Composites, 24(2), 269-279.

Ajdukiewicz, A. B. and Kliszczewicz, A. T., (2007). "Comparative tests of beams and columns made of recycled aggregate concrete and natural aggregate concrete." Journal of Advanced Concrete Technology, 5(2), 259-273.

Akcay, B., Agar-Ozbek, A. S., Bayramov, F., Atahan, H. N., Sengul, C. and Tasdemir, M. A., (2012). "Interpretation of aggregate volume fraction effects on fracture behavior of concrete." Construction and Building Materials, 28(1), 437-443.

Aksut, Y. S. and Yetgin, S., (2017). "The usability of volcanic rocks from Upper Euphrates part in the
Eastern Anatolia Region as concrete aggregate." Sigma Journal of Engineerng and Natural Sciences, 4, 593-608.

Alexander, M. G., (1996). "Aggregates and the deformation properties of concrete." Materials Journal, 93(6), 569-577.

Alexander, M. G. and Milne, T. I., (1995). "Influence of cement blend and aggregate type on the stress-strain behavior and elastic modulus of concrete." Materials Journal, 92(3), 227-235.

Alonso, E., Martínez, L., Martínez, W. and Villaseñor, L., (2002). "Mechanical properties of concrete elaborated with igneous aggregates." Cement and Concrete Research, 32(2), 317-321.

Amario, M., Rangel, C. S., Pepe, M. and Toledo Filho, R. D., (2017). "Optimization of normal and high strength recycled aggregate concrete mixtures by using packing model." Cement and Concrete Composites, 84, 83-92.

Andal, J., Shehata, M. and Zacarias, P., (2016). "Properties of concrete containing recycled concrete aggregate of preserved quality." Construction and Building Materials, 125, 842-855.

Arezoumandi, M., Drury, J., Volz, J. S. and Kamal, H. K., (2015a). "Effect of recycled concrete aggregate replacement level on the shear strength of reinforced concrete beams." Materials Journal, 112(4), 559-568.

Arezoumandi, M., Smith, A., Volz, J. S. and Khayat, K. H., (2014). "An experimental study on shear strength of reinforced concrete beams with $100 \%$ recycled concrete aggregate." Construction and Building Materials, 53(0), 612-620.

Arezoumandi, M., Smith, A., Volz, J. S. and Khayat, K. H., (2015b). "An experimental study on flexural strength of reinforced concrete beams with 100\% recycled concrete aggregate." Engineering Structures, 88, 154-162.

Arioglu, N., Canan Girgin, Z. and Arioglu, E., (2006). "Evaluation of ratio between splitting tensile strength and compressive strength for concretes up to 120 $\mathrm{MPa}$ and its application in strength criterion." $A C I$ Materials Journal, 103(1), 18-24.

Ashour, S. A., (2000). "Effect of compressive strength and tensile reinforcement ratio on flexural behavior of high-strength concrete beams." Engineering Structures, 22(5), 413-423.

ASTM-C31M., (2003). "Standard practice for making and curing concrete test specimens in the field." Pennsylvania, USA: American Society of Testing and Materials.

Atahan, H. N., Oktar, O. N. and Taşdemir, M. A., (2011). "Factors determining the correlations between high strength concrete properties." Construction and Building Materials, 25(5), 2214-2222.

Bakhsh, A. H., Wafa, F. F. and Akhtaruzzaman, A. A., (1990). "Torsional behavior of plain high-strength concrete beams." Structural Journal, 87(5).

Bažant, Z. P. and Cedolin, L., (1993). "Why direct 
tension test specimens break flexing to the side." Journal of Structural Engineering, 119(4), 1101-1113. Bažant, Z. P. and Yavari, A., (2005). "Is the cause of size effect on structural strength fractal or energeticstatistical?" Engineering Fracture Mechanics, 72(1), 1-31.

Becker, P. , Corallo, P., Domínguez, J., Ríos, C., Gea, I. and Canãri, J., (2018). "Concretes with low paste and low cement content durability and sustainability." ACI Special Publication, 326, 52.1-52.10.

Bilodeau, A. and Malhotra, V. M., (1992). "Concretes incorporating high volumes of ASTM Class F fly ashes: mechanical properties and resistance to deicing salt scaling and to chloride-ion penetration." ACI Special Publication, 132, 319-349.

Bordelon, A., Cervantes, V. and Roesler, J. R., (2009). "Fracture properties of concrete containing recycled concrete aggregates." Magazine of Concrete Research, 61(9), 665-670.

Bravo, M., Brito, J. d., Pontes, J. and Evangelista, L., (2015a). "Performance of concrete made with recycled aggregates from Portuguese CDW recycling plants." Key Engineering Materials, 634, 193-205.

Bravo, M., de Brito, J., Evangelista, L. and Pacheco, J., (2017). "Superplasticizer's efficiency on the mechanical properties of recycled aggregates concrete: influence of recycled aggregates composition and incorporation ratio." Construction and Building Materials, 153, 129-138.

Bravo, M., Santos Silva, A., de Brito, J. and Evangelista, L., (2015b). "Microstructure of concrete with aggregates from construction and demolition waste recycling plants." Microscopy and Microanalysis, 22(1), 149-167.

Butler, L., (2012). "Evaluation of recycled concrete aggregate performance in structural concrete." University of Waterloo, Ontario, Canada.

Butler, L., West, J. S. and Tighe, S. L., (2013). "Effect of recycled concrete coarse aggregate from multiple sources on the hardened properties of concrete with equivalent compressive strength." Construction and Building Materials, 47, 1292-1301.

Carette, G., Bilodeau, A., Chevrier, R. L. and Malhotra, V. M., (1993). "Mechanical properties of concrete incorporating high volumes of fly ash from sources in the U.S." Materials Journal, 90(6), 535-544.

Casuccio, M., Torrijos, M. C., Giaccio, G. and Zerbino, R., (2008). "Failure mechanism of recycled aggregate concrete." Construction and Building Materials, 22(7), 1500-1506.

Cetin, A. and Carrasquillo, R. L., (1998). "Highperformance concrete: influence of coarse aggregates on mechanical properties." Materials Journal, 95(3), 252-259.

Chang, T. P., Lin, S. H., Lin, H. C. and Lin, P. R., (2001). "Effects of various fineness moduli of fine aggregate on engineering properties of high-performance concrete." Journal of the Chinese Institute of
Engineers, 24(3), 289-300.

Choi, W.-C., Yun, H.-D. and Kim, S.-W., (2012). "Flexural performance of reinforced recycled aggregate concrete beams." Magazine of Concrete Research, 64(9), 837-848.

Cülfik, M. S. and Özturan, T., (2010). "Mechanical properties of normal and high strength concretes subjected to high temperatures and using image analysis to detect bond deteriorations." Construction and Building Materials, 24(8), 1486-1493.

Demir, I., (2009). "Investigation of mechanical properties of concrete produced with waste granites aggregates." Scientific Research and Essay, 4, 267274.

Dilbas, H., Şimşek, M. and Çakır, Ö., (2014). “An investigation on mechanical and physical properties of recycled aggregate concrete (RAC) with and without silica fume." Construction and Building Materials, 61, 50-59.

Donza, H., Cabrera, O. and Irassar, E. F., (2002). "Highstrength concrete with different fine aggregate." Cement and Concrete Research, 32(11), 1755-1761.

Dossey, T., McCullough, B. F. and Dumas, A., (1994). "Effects of aggregate blends on the properties of Portland Cement concrete pavements." Texas, USA: Center for Transportation Research - The University of Texas at Austin.

Durán-Herrera, A., Juárez, C. A., Valdez, P. and Bentz, D. P., (2011). "Evaluation of sustainable high-volume fly ash concretes." Cement and Concrete Composites, 33(1), 39-45.

Etxeberria, M., Mari, A. R. and Vazquez, E., (2007a). "Recycled aggregate concrete as structural material." Materials and Structures, 40(5), 529-541.

Etxeberria, M., Vazquez, E., Mari, A. and Barra, M., (2007b). "Influence of amount of recycled coarse aggregates and production process on properties of recycled aggregate concrete." Cement and Concrete Research, 37(5), 735-742.

Eurocode 0, (2002). "Eurocode 0: Basis of structural design." Brussels, Belgium: CEN.

Eurocode 2, (2008). "Eurocode 2 - Design of concrete structures: Part 1-1: General rules and rules for buildings." Brussels, Belgium: CEN.

Eurocode 2, (2020). "PT1prEN1992-1-1:2017-10 Eurocode 2: Part 1-1. Second complete interim draft of October 2017." CEN/TC-250/SC-2.

Evangelista, L., (2014). "Concrete with fine concrete recycled aggregates (Comportamento de betões com agregados finos reciclados de betão)." Thesis ( $\mathrm{PhD})$. Instituto Superior Técnico, University of Lisbon, Portugal.

Evangelista, L. and de Brito, J., (2017). "Flexural behaviour of reinforced concrete beams made with fine recycled concrete aggregates." KSCE Journal of Civil Engineering, 21(1), 353-363.

fib, (2008). "Bulletin n. 42: Constitutive modelling of high strength / high performance concrete." Lausanne, 
Switzerland: $f i b$.

fib, (2010). "Bulletin n. 65: Model Code 2010 final draft. Volume 1." Lausanne, Switzerland: fib.

fib, (2013). "Bulletin n. 70: Code-type models for concrete behaviour." Lausanne, Switzerland: fib.

Freyne, S. F., Russell, B. W., Bush Jr, T. D. and Hale, W. M., (2004). "Comparing different cements in highperformance concrete." Materials Journal, 101(6), 435-441.

Gardner, N. J., (1990). "Effect of temperature on the early-age properties of Type I, Type II, and Type III/fly ash concretes." Materials Journal, 87(1), 6878.

Gardner, N. J., Sau, P. L. and Cheung, M. S., (1988). "Strength development and durability of concretes cast and cured at 0 C." Materials Journal, 85(6), 529536.

Gerges, N. N., Issa, C. A. and Fawaz, S., (2015). "Effect of construction joints on the splitting tensile strength of concrete." Case Studies in Construction Materials, 3, 83-91.

Gholampour, A. and Ozbakkaloglu, T., (2017). "Performance of sustainable concretes containing very high volume Class-F fly ash and ground granulated blast furnace slag." Journal of Cleaner Production, 162, 1407-1417.

Gholampour, A. and Ozbakkaloglu, T., (2018). "Timedependent and long-term mechanical properties of concretes incorporating different grades of coarse recycled concrete aggregates." Engineering Structures, 157, 224-234.

Giaccio, G. and Zerbino, R., (1998). "Failure mechanism of concrete: combined effects of coarse aggregates and strength level." Advanced Cement Based Materials, 7(2), 41-48.

Gomez-Soberon, J. M. V., (2002). "Porosity of recycled concrete with substitution of recycled concrete aggregate - An experimental study." Cement and Concrete Research, 32(8), 1301-1311.

Gonzalez-Corominas, A. and Etxeberria, M., (2014). "Properties of high performance concrete made with recycled fine ceramic and coarse mixed aggregates." Construction and Building Materials, 68, 618-626.

Gonzalez-Corominas, A., Etxeberria, M. and Poon, C.-s., (2017). "Influence of the quality of recycled aggregates on the mechanical and durability properties of high performance concrete." Waste and Biomass Valorization, 8(5), 1421-1432.

González-Fonteboa, B. and Martínez-Abella, F., (2004). "Shear strength of concrete with recycled aggregates." International RILEM Conference on the Use of Recycled Materials in Buildings and Structures, Barcelona, Spain.

González-Fonteboa, B. and Martínez-Abella, F., (2005). "Recycled aggregates concrete: aggregate and mix properties." Materiales De Construccion, 55(279), 53-66.

González-Fonteboa, B., Martínez-Abella, F., Eiras-
Lopez, J. and Seara-Paz, S., (2011). "Effect of recycled coarse aggregate on damage of recycled concrete." Materials and Structures, 44(10), 17591771.

Gulvanessian, H., Calgaro, J. A. and Holicky, M., (2002). "Designers' guide to EN1990 Eurocode: Basis of structural design." London, United Kingdom: Thomas Telford.

Guo, M., Alam, S. Y., Bendimerad, A. Z., Grondin, F., Rozière, E. and Loukili, A., (2017). "Fracture process zone characteristics and identification of the microfracture phases in recycled concrete." Engineering Fracture Mechanics, 181, 101-115.

Gupta, P. , Khaudhair, Z. and Ahuja, A., (2016). "A new method for proportioning recycled concrete." Structural Concrete, 17(4), 677-687.

Gutierrez, P. A. and Canovas, M. F., (1995). "The modulus of elasticity of high performance concrete." Materials and Structures, 28(10), 559-568.

Hamad, B. and Dawi, A., (2017). "Sustainable normal and high strength recycled aggregate concretes using crushed tested cylinders as coarse aggregates." Case Studies in Construction Materials, 7, 228-239.

Honfi, D., Mårtensson, A. and Thelandersson, S., (2012). "Reliability of beams according to Eurocodes in serviceability limit state." Engineering Structures, 35, 48-54.

Huang, C.-H., Lin, S.-K., Chang, C.-S. and Chen, H.-J., (2013). "Mix proportions and mechanical properties of concrete containing very high-volume of Class $\mathrm{F}$ fly ash." Construction and Building Materials, 46, 71-78.

Huda, S. B. and Alam, M. S., (2014). "Mechanical behavior of three generations of $100 \%$ repeated recycled coarse aggregate concrete." Construction and Building Materials, 65, 574-582.

Iravani, S., (1996). "Mechanical properties of highperformance concrete." Materials Journal, 93(5).

ISO2394, (1998) "General principles on reliability for structures.” Brussels, Belgium: CEN.

Jin, X. and Li, Z., (2003). "Effects of mineral admixture on properties of young concrete." Journal of Materials in Civil Engineering, 15(5), 435-442.

Kang, T. H.-K., Kim, W., Kwak, Y.-K. and Sung-Gul, H., (2014). "Flexural testing of reinforced concrete beams with recycled concrete aggregates (with Appendix)." ACI Structural Journal, 111(3), 607-616.

Khaliq, W. and Taimur., (2018). "Mechanical and physical response of recycled aggregates highstrength concrete at elevated temperatures." Fire Safety Journal, 96, 203-214.

Khanzadi, M. and Behnood, A., (2009). "Mechanical properties of high-strength concrete incorporating copper slag as coarse aggregate." Construction and Building Materials, 23(6), 2183-2188.

Kheder, G. F. and Al-Windaw, S. A., (2005). "Variation in mechanical properties of natural and recycled aggregate concrete as related to the strength of their 
binding mortar." Materials and Structures, 38(281), 701-709.

Kim, J.-E., Park, W.-S., Jang, Y.-I., Kim, S.-W., Kim, S.W., Nam, Y.-H., Kim, D.-G. and Rokugo, K., (2016). "Mechanical properties of energy efficient concretes made with binary, ternary, and quaternary cementitious blends of fly ash, blast furnace slag, and silica fume." International Journal of Concrete Structures and Materials, 10(3), 97-108.

Kim, J.-K., Han, S. H. and Song, Y. C., (2002). "Effect of temperature and aging on the mechanical properties of concrete: Part I. Experimental results." Cement and Concrete Research, 32(7), 1087-1094.

Kim, K., Shin, M. and Cha, S., (2013). "Combined effects of recycled aggregate and fly ash towards concrete sustainability." Construction and Building Materials, 48, 499-507.

Kliszczewicz, A. and Ajdukiewicz, A., (2002). "Differences in instantaneous deformability of HS/HPC according to the kind of coarse aggregate." Cement and Concrete Composites, 24(2), 263-267.

Kou, S. C. and Poon, C. S., (2015). "Effect of the quality of parent concrete on the properties of high performance recycled aggregate concrete." Construction and Building Materials, 77, 501-508.

Kou, S. C., Poon, C. S. and Chan, D., (2007). "Influence of fly ash as cement replacement on the properties of recycled aggregate concrete." Journal of Materials in Civil Engineering, 19(9), 709-717.

Koulouris, A., Limbachiya, M. C., Fried, A. N. and Roberts, J. J., (2004). "Use of recycled aggregate in concrete application: Case studies." In: Proc. of International Conference on Sustainable Waste Management and Recycling: Challenges and Opportunities, 14-15, London, UK.

Lam, L., Wong, Y. L. and Poon, C. S., (1998). "Effect of fly ash and silica fume on compressive and fracture behaviors of concrete." Cement and Concrete Research, 28(2), 271-283.

Laneyrie, C., Beaucour, A.-L., Green, M. F., Hebert, R. L., Ledesert, B. and Noumowe, A., (2016). "Influence of recycled coarse aggregates on normal and high performance concrete subjected to elevated temperatures." Construction and Building Materials, 111, 368-378.

Langan, B. W., Weng, K. and Ward, M. A., (2002). "Effect of silica fume and fly ash on heat of hydration of Portland cement." Cement and Concrete Research, 32(7), 1045-1051.

Lee, J.-H. and Yoon, Y.-S., (2015). "The effects of cementitious materials on the mechanical and durability performance of high-strength concrete." KSCE Journal of Civil Engineering, 19(5), 13961404.

Lotfy, A. and Al-Fayez, M., (2015). "Performance evaluation of structural concrete using controlled quality coarse and fine recycled concrete aggregate." Cement and Concrete Composites, 61, 36-43.
Madsen, H., Krenk. S. and Lind, N., (1986), "Methods of structural safety." New Jersey, United States of America: Dover Publications, 407 pages.

Malárics, V. and Müller, H. S., (2010). "Evaluation of the splitting tension test for concrete from a fracture mechanical point of view." In: B. H. Oh, et al., Eds. Proceedings of Fracture Mechanics of Concrete and Concrete Structures - Assessment, Durability, Monitoring and Retrofitting of Concrete Structures, Seoul, South Korea, 709-716.

Manzi, S., Mazzotti, C. and Bignozzi, M. C., (2013). "Short and long-term behavior of structural concrete with recycled concrete aggregate." Cement and Concrete Composites, 37, 312-318.

Marques, P. F., Chastre, C. and Nunes, Â., (2013). "Carbonation service life modelling of RC structures for concrete with Portland and blended cements." Cement and Concrete Composites, 37, 171-184.

Mehta, P. K. and Monteiro, P. J., (2006). "Concrete: microstructure, properties and materials." $3 \mathrm{rd}$ ed. New York, United States of America: McGraw-Hill, 659 pages.

Mesbah, H. A., Lachemi, M. and Aitcin, P. C., (2002). "Determination of elastic properties of highperformance concrete at early ages." Materials Journal, 99(1), 37-41.

Mirza, S. A., MacGregor, J. G. and Hatzinikolas, M., (1979). "Statistical descriptions of strength of concrete." ASCE Journal of the Structural Division, 105(6), 1021-1037.

Mohammed, T. U., Ahmed, T., Apurbo, S. M., Mallick, T. A., Shahriar, F., Munim, A. and Awal, M. A., (2017). "Influence of chemical admixtures on fresh and hardened properties of prolonged mixed concrete." Advances in Materials Science and Engineering, 2017, 9187627.

Mouret, M., Bascoul, A. and Escadeillas, G., (1997). "Drops in concrete strength in summer related to the aggregate temperature." Cement and Concrete Research, 27(3), 345-357.

Muhammad, A. K. and Sankaranarayanan, K. M., (2016). "Investigations on concrete with recycled concrete as coarse aggregate." International Journal of Scientific and Engineering Research, 7(10), 213218.

Naik, T. R., Kraus, R. N. and Kumar, R., (2011). "Influence of types of coarse aggregates on the coefficient of thermal expansion of concrete." Journal of Materials in Civil Engineering, 23(4), 467-472. doi: 10.1061/(ASCE)MT.19435533.0000198

Naik, T. R., Singh, S. S. and Ramme, B. W., (1998). "Mechanical properties and durability of concrete made with blended fly ash." Materials Journal, 95(4), 454-460.

Noguchi, T., Tomosawa, F., Nemati, K. M., Chiaia, B. M. and Fantilli, A. P., (2009). "A practical equation for elastic modulus of concrete." ACI Structural Journal, 
106(5), 690-696.

Oluokun, F. Burdette, E. G. and Deatherage, J. H., (1991). "Splitting tensile strength and compressive strength relationships at early ages." Materials Journal, 88(2).

Omary, S., Ghorbel, E., Wardeh, G. and Nguyen, M. D., (2018). "Mix design and recycled aggregates effects on the concrete's properties." International Journal of Civil Engineering, 16(8), 973-992.

Ozbakkaloglu, T., Gholampour, A. and Xie, T., (2018). "Mechanical and durability properties of recycled aggregate concrete: effect of recycled aggregate properties and content." Journal of Materials in Civil Engineering, 30(2), 04017275.

Pacheco, J., de Brito, J., Chastre, C. and Evangelista, L., (2019a). "Experimental investigation on the variability of the main mechanical properties of recycled aggregate concrete." Construction and Building Materials, 201, 110-120.

Pacheco, J., de Brito, J., Chastre, C. and Evangelista, L., (2019b) "Probabilistic conversion of the compressive strength of cubes to cylinders of natural and recycled aggregate concrete specimens." Materials, 12(2), 280-290.

Pacheco, J., de Brito, J., Ferreira, J. and Soares, D., (2015). "Destructive horizontal load tests of full-scale recycled aggregate concrete structures." $A C I$ Structural Journal, 112(6), 815-826.

Park, W.-S., Kim, J.-E., Eom, N.-Y., Kim, S.-W., Kim, D.-G. and Cho, M.-S., (2013). "Mechanical properties of high strength concrete using mineral admixtures." Applied Mechanics and Materials, 372, 235-238.

Paul, S. C., (2011). "Mechanical behaviour and durability performance of concrete containing recycled concrete aggregate." Thesis (MSc). University of Stellenbosch, Cape Town, South Africa.

Pedro, D., de Brito, J. and Evangelista, L., (2014). "Influence of the use of recycled concrete aggregates from different sources on structural concrete." Construction and Building Materials, 71, 141-151.

Pepe, M., (2015). “A conceptual model for designing recycled aggregate concrete for structural applications." Thesis (PhD). University of Salerno, Italy.

Piasta, W., Góra, J. and Budzyński, W., (2017). "Stressstrain relationships and modulus of elasticity of rocks and of ordinary and high performance concretes." Construction and Building Materials, 153, 728-739.

Proske, T., Hainer, S., Rezvani, M. and Graubner, C.-A., (2014). "Eco-friendly concretes with reduced water and cement content - Mix design principles and application in practice." Construction and Building Materials, 67, 413-421.

Pul, S., (2008). "Experimental investigation of tensile behaviour of high strength concrete." Indian Journal of Engineering and Materials Sciences, 15, 467-472.

Razaqpur, A. G., Fathifazl, G., Isgor, B., Abbas, A., Fournier, B. and Foo, S., (2010). "How to produce high quality concrete mixes with recycled concrete aggregate." In: J. Zh. Xiao, et al., Eds. $2^{\text {nd }}$ International Conference on Waste Engineering Management - ICWEM 2010, Shanghai, China, RILEM Publications SARL, 11-35.

Remesar, J. C., Vera, S. and Lopez, M., (2017). "Assessing and understanding the interaction between mechanical and thermal properties in concrete for developing a structural and insulating material." Construction and Building Materials, 132, 353-364.

Rocco, C., Guinea, G. V., Planas, J. and Elices, M., (1999a). "Size effect and boundary conditions in the Brazilian test: Experimental verification." Materials and Structures, 32(3), 210-217.

Rocco, C., Guinea, G. V., Planas, J. and Elices, M., (1999b). "Size effect and boundary conditions in the brazilian test: theoretical analysis." Materials and Structures, 32(6), 437-444.

Sadati, S. and Khayat, K. H., (2016). "Field performance of concrete pavement incorporating recycled concrete aggregate." Construction and Building Materials, 126, 691-700.

Saito, M. and Kawamura, M., (1989). "Effect of fly ash and slag on the interfacial zone between cement and aggregate." ACI Special Publication, 114, 669-688.

Saouma, V. E., Broz, J. J., Brühwiler, E. and Boggs, H. L., (1991). "Effect of aggregate and specimen size on fracture properties of dam concrete." Journal of Materials in Civil Engineering, 3(3), 204-218.

Siddique, R., (2004). "Performance characteristics of high-volume Class F fly ash concrete." Cement and Concrete Research, 34(3), 487-493.

Sidorova, A., Vazquez-Ramonich, E., Barra-Bizinotto, M., Roa-Rovira, J. J. and Jimenez-Pique, E., (2014). "Study of the recycled aggregates nature's influence on the aggregate-cement paste interface and ITZ." Construction and Building Materials, 68, 677-684.

Silva, R. V., de Brito, J. and Dhir, R. K., (2016). "Establishing a relationship between the modulus of elasticity and compressive strength of recycled aggregate concrete." Journal of Cleaner Production, 112(4), 2171-2186.

Sivasundaram, V., Carette, G. G. and Malhotra, V. M., (1989). "Properties of concrete incorporating low quantity of cement and high volumes of low-calcium fly ash." ACI Special Publication, 114, 45-71.

Sivasundaram, V., Carette, G. G. and Malhotra, V. M., (1991). "Mechanical properties, creep, and resistance to diffusion of chloride ions of concretes incorporating high volumes of ASTM Class F fly ashes from seven different sources." Materials Journal, 88(4).

Soleymani Ashtiani, M., Scott, A. N. and Dhakal, R. P., (2013). "Mechanical and fresh properties of highstrength self-compacting concrete containing class $\mathrm{C}$ fly ash." Construction and Building Materials, 47, 1217-1224.

Tangchirapat, W., Rattanashotinunt, C., Buranasing, R. 
and Jaturapitakkul, C., (2013). "Influence of fly ash on slump loss and strength of concrete fully incorporating recycled concrete aggregates." Journal of Materials in Civil Engineering, 25(2), 243-251.

Tasdemir, M. A. and Karihaloo, B. L., (2001). "Effect of aggregate volume fraction on the fracture parameters of concrete: a meso-mechanical approach." Magazine of Concrete Research, 53(6), 405-415. doi: 10.1680/macr.2001.53.6.405

Teranishi, K., Dosho, Y., Narikawa, M. and Kikuchi, M., (1998). "Application of recycled aggregate concrete for structural concrete: Part 3 - Production of recycled aggregate by real-scale plant and quality of recycled aggregate concrete." In: International Symposium on Sustainable construction: Use of recycled concrete aggregate, London, UK.

Tibbetts, C. M., Perry, M. C., Ferraro, C. C. and Hamilton, H. R., (2018). "Aggregate correction factors for concrete elastic modulus prediction." Structural Journal, 115(4), 931-941. doi: $10.14359 / 51701914$

Tufail, M., Shahzada, K., Gencturk, B. and Wei, J., (2017). "Effect of elevated temperature on mechanical properties of limestone, quartzite and granite concrete." IJCSM, 11(1), 17-28. doi: 10.1007/s40069-016-0175-2

Uzal, B., Turanli, L. and Mehta, P. K., (2007). "Highvolume natural pozzolan concrete for structural applications." Materials Journal, 104(5), 535-538. doi: 10.14359/18910

van Mier, J. and Mechtcherine, V., (2007). "Minimum demands for deformation-controlled uniaxial tensile tests." In J. Planas, Ed., Experimental Determination of the Stress-Crack Opening Curve for Concrete in Tension - Final report of RILEM Technical Committee TC 187-SOC (pp. 5-11): RILEM Publications SARL.

Vogel, H. M. and Svecova, D., (2012). "Evaluation of elastic modulus for high-strength concrete." Materials Journal, 109(3). doi: 10.14359/51683821

Yagishita, F., Sano, M. and Yamada, M., (1993). "Behaviour of reinforced concrete beams containing recycled coarse aggregate." Third International

\author{
Notation \\ Abbreviations \\ BS - basalt \\ CAN - crushed natural aggregates \\ $\mathrm{CoV}$ - coefficient of variation \\ CRA - crushed recycled aggregates \\ FA - fly ash \\ GGBS - ground granulated blast-furnace slag \\ GR - granite \\ ITZ - interfacial transition zone \\ LS - Limestone \\ OPC - ordinary Portland cement \\ QZ - quartzite \\ RA - recycled concrete aggregates
}

RILEM Symposium on Demolition and Reuse of Concrete and Masonry, Odense, Denmark.

Yanagi, K., Kasai, Y., Kaga, S. and Abe, M., (1998). "Experimental study on the applicability of recycled aggregate concrete to cast-in-place concrete pile." In: Proc. of International Symposium on Sustainable construction: Use of recycled concrete aggregate, London, UK.

Yang, K., Chung, H. and Ashour, A., (2008). "Influence of type and replacement level of recycled aggregates on concrete properties." ACI Materials Journal, 105(3), 289-296.

Yiğiter, H., Yazıcı, H. and Aydın, S., (2007). "Effects of cement type, water/cement ratio and cement content on sea water resistance of concrete." Building and Environment, 42(4), 1770-1776.

Yildirim, S. T., Meyer, C. and Herfellner, S., (2015). "Effects of internal curing on the strength, drying shrinkage and freeze-thaw resistance of concrete containing recycled concrete aggregates." Construction and Building Materials, 91(0), 288-296.

Yoshitake, B. I., Wong, H., Ishida, T. and Nassif, A. Y., (2014). "Thermal stress of high volume fly-ash (HVFA) concrete made with limestone aggregate." Construction and Building Materials, 71, 216-225.

Yoshitake, I., Komure, H., Nassif, A. Y. and Fukumoto, S., (2013). "Tensile properties of high volume fly-ash (HVFA) concrete with limestone aggregate." Construction and Building Materials, 49, 101-109.

Zega, C. J. and Di Maio, A. A., (2006). "Recycled concrete exposed to high temperatures." Magazine of Concrete Research, 58(10), 675-682.

Zega, C. J. and Di Maio, A. A., (2009). "Recycled concrete made with different natural coarse aggregates exposed to high temperature." Construction and Building Materials, 23(5), 20472052.

Zega, C. J. and Di Maio, A. A., (2011). "Recycled concretes made with waste ready-mix concrete as coarse aggregate." Journal of Materials in Civil Engineering, 23(3), 281-286.

RNA - rounded natural aggregates

SF - silica fume

SLS - serviceability limit-state

SS - sandstone

$\underline{\text { Symbols }}$

$E_{c}$ - Young's modulus of concrete

$E_{c m}$ - average $E_{c}$

$f_{c}$ - compressive strength of concrete

$f_{c k}$ - characteristic $f_{c}$

$f_{c m}$ - average $f_{c}$

$f_{c t}$ - tensile strength of concrete

$f_{c t m}$ - average $f_{c t}$

$f_{c t m, s p l t}$ - average splitting tensile strength 
$\alpha$ - Eurocode/Model Code aggregate correction factor

$\alpha_{R, F O R M}$ - sensitivity factor of a leading resistance variable (EN 1990)

$\Delta_{a b s}$ - absolute errors of the proposed models in comparison to the data

$\Delta_{r e l}$ - relative errors of the proposed models in comparison to the data

$\theta_{E}$ - model uncertainty of $f_{c}$ vs. $E_{c}$ constitutive rela- tionship

$\theta_{E d}$ - estimate of the design value of $\theta_{E}$

$\theta_{f c t}$ - model uncertainty of $f_{c}$ vs. $f_{c t}$ constitutive relationship

$\theta_{f c t d}$ - estimate of the design value of $\theta_{f c t}$

$\theta_{f c t k 0.05}-5 \%$ fractile of $\theta_{f c t}$

$\theta_{\text {fctk } 0.95}-95 \%$ fractile of $\theta_{f c t}$ 


\section{Appendix}

Table A. $1 \mathrm{fc}$ vs. Ec: Statistics of the $\phi 150 \mathrm{~mm}$ cylinders. More than 7 mixes only.

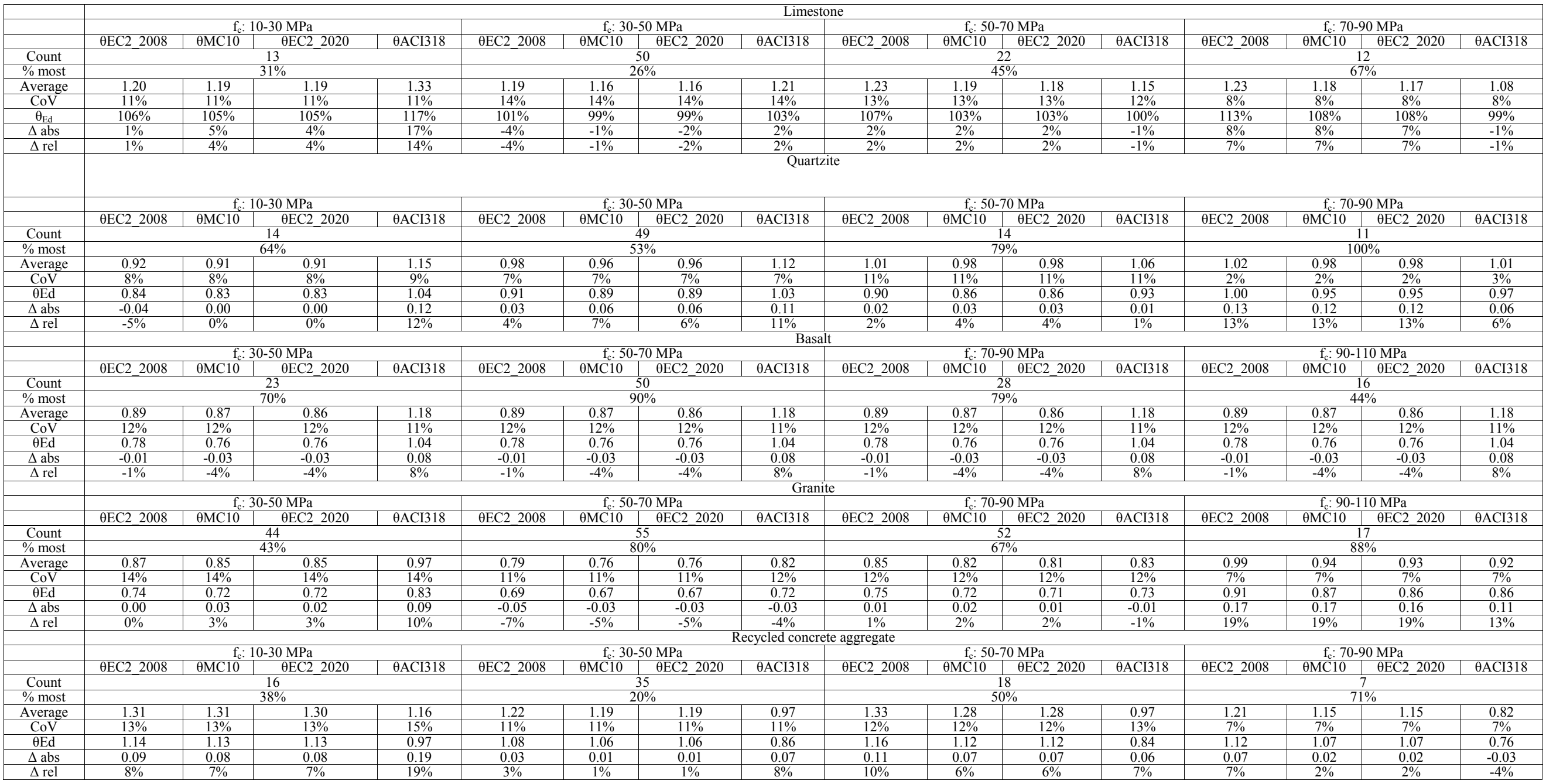

Note: "\% most" is the maximum percentage of mixes coming from a single paper 
Table A. 2: $\mathrm{f}_{\mathrm{c}}$ vs. $\mathrm{E}_{\mathrm{c}}$ : Statistics of the $\phi 100 \mathrm{~mm}$ cylinders. More than 7 mixes only.

\begin{tabular}{|c|c|c|c|c|c|c|c|c|c|c|c|c|c|c|c|c|}
\hline & \multicolumn{16}{|c|}{ Limestone } \\
\hline & \multicolumn{4}{|c|}{$f_{c}: 10-30 \mathrm{MPa}$} & \multicolumn{4}{|c|}{$f_{c}: 30-50 \mathrm{MPa}$} & \multicolumn{4}{|c|}{$f_{c}: 50-70 \mathrm{MPa}$} & \multicolumn{4}{|c|}{$f_{c}: 70-90 \mathrm{MPa}$} \\
\hline & eEC2_2008 & өMC10 & 9EC2_2020 & өACl318 & eEC2_2008 & өMC10 & OEC2_2020 & $\theta \mathrm{ACl} 318$ & 9EC2_2008 & өMC10 & eEC2_2020 & $\theta \mathrm{ACl} 318$ & 9EC2_2008 & $\theta \mathrm{MC} 10$ & OEC2_2020 & өACI318 \\
\hline Count & \multicolumn{4}{|c|}{10} & \multicolumn{4}{|c|}{48} & \multicolumn{4}{|c|}{42} & \multicolumn{4}{|c|}{25} \\
\hline$\%$ most & \multicolumn{4}{|c|}{$40 \%$} & \multicolumn{4}{|c|}{$44 \%^{*}$} & \multicolumn{4}{|c|}{$57 \%^{*}$} & \multicolumn{4}{|c|}{$36 \%$} \\
\hline Average & 1.01 & 1.01 & 1.00 & 1.13 & 1.04 & 1.01 & 1.01 & 1.05 & 1.13 & 1.09 & 1.08 & 1.05 & 1.15 & 1.10 & 1.10 & 1.01 \\
\hline STdev & 0.16 & 0.15 & 0.15 & 0.18 & 0.13 & 0.13 & 0.13 & 0.14 & 0.13 & 0.13 & 0.12 & 0.12 & 0.15 & 0.14 & 0.14 & 0.13 \\
\hline \multirow[t]{4}{*}{$\mathrm{CoV}$} & $15 \%$ & $15 \%$ & $15 \%$ & $16 \%$ & $13 \%$ & $13 \%$ & $13 \%$ & $13 \%$ & $12 \%$ & $12 \%$ & $12 \%$ & $11 \%$ & $13 \%$ & $13 \%$ & $13 \%$ & $12 \%$ \\
\hline & \multirow{2}{*}{\multicolumn{16}{|c|}{ Sandstone }} \\
\hline & $\mathrm{f}_{\mathrm{c}}: 10-30 \mathrm{MPa}$ & & & & & & & & & & & & \multicolumn{4}{|c|}{$\mathrm{f}_{\mathrm{c}}: 70-90 \mathrm{MPa}$} \\
\hline & $\theta_{\mathrm{EC} 2,2008}$ & $\theta_{\mathrm{MC} 10}$ & $\theta_{\mathrm{EC} 2,2020}$ & $\theta_{A C 1318}$ & $\theta_{\mathrm{EC} 2,2008}$ & $\theta_{\mathrm{MC} 10}$ & $\theta_{\mathrm{EC} 2,2020}$ & $\theta_{\mathrm{ACI} 1318}$ & $\theta_{\mathrm{EC} 2,2008}$ & $\theta_{\mathrm{MC} 10}$ & $\theta_{\mathrm{EC} 2,2020}$ & $\theta_{\mathrm{AC} 1318}$ & $\theta_{\mathrm{EC} 2,2008}$ & $\theta_{\mathrm{MC} 10}$ & $\theta_{\mathrm{EC} 2,2020}$ & $\theta_{\mathrm{ACl131}}$ \\
\hline Count & & & & & \multicolumn{4}{|c|}{16} & \multirow{2}{*}{\multicolumn{4}{|c|}{$\frac{13}{62 \%}$}} & & & & \\
\hline$\%$ most & & & & & & & & & & & & & & & & \\
\hline Average & & & & & 1.17 & 1.15 & 1.15 & 0.94 & 1.08 & 1.04 & 1.03 & 0.77 & 1.04 & 0.99 & 0.99 & 0.68 \\
\hline STdev & & & & & 0.10 & 0.10 & 0.10 & 0.08 & 0.08 & 0.08 & 0.08 & 0.06 & 0.04 & 0.04 & 0.04 & 0.03 \\
\hline $\mathrm{CoV}$ & & & & & $9 \%$ & $8 \%$ & $8 \%$ & $8 \%$ & $8 \%$ & $8 \%$ & $8 \%$ & $8 \%$ & $4 \%$ & $4 \%$ & $4 \%$ & $4 \%$ \\
\hline & & & & & & & & & & & & & & & & \\
\hline & & $\mathrm{f}_{\mathrm{c}}: 10$ & $\mathrm{MPa}$ & & & $f_{c}: 30$ & $\mathrm{MPa}$ & & & $f_{c}: 50$ & $\mathrm{MPa}$ & & & $f_{c}: 70$ & $\mathrm{MPa}$ & \\
\hline & $\theta_{\mathrm{EC} 2,2008}$ & $\theta_{\mathrm{MC} 10}$ & $\theta_{E C 2,2020}$ & $\theta_{\mathrm{AC} 1318}$ & $\theta_{\mathrm{EC} 2,2008}$ & $\theta_{\mathrm{MC10}}$ & $\theta_{\mathrm{EC} 2,2020}$ & $\theta_{\mathrm{AC} 1318}$ & $\theta_{\mathrm{EC} 2,2008}$ & $\theta_{\mathrm{MC} 10}$ & $\theta_{\mathrm{EC} 2,2020}$ & $\theta_{\mathrm{ACl131}}$ & $\theta_{\mathrm{EC} 2,2008}$ & $\theta_{\mathrm{MC} 10}$ & $\theta_{\mathrm{EC} 2,2020}$ & $\theta_{\mathrm{AC} 1318}$ \\
\hline Count & & & & & & & & & & & & & & & & \\
\hline$\%$ most & & & & & & & & & & & & & & & & \\
\hline Average & & & & & 0.82 & 0.80 & 0.80 & 1.11 & & & & & & & & \\
\hline STdev & & & & & 0.17 & 0.16 & 0.16 & 0.22 & & & & & & & & \\
\hline $\mathrm{CoV}$ & & & & & $21 \%$ & $20 \%$ & $20 \%$ & $20 \%$ & & & & & & & & \\
\hline & & & & & & & & & & & & & & & & \\
\hline & & $f_{c}: 10$ & $\mathrm{MPa}$ & & & $f_{c}: 30$ & $\mathrm{MPa}$ & & & $f_{c}: 50$ & $\mathrm{MPa}$ & & & $f_{c}: 70$ & $\mathrm{MPa}$ & \\
\hline & $\theta_{\mathrm{EC} 2,2008}$ & $\theta_{\mathrm{MC} 10}$ & $\theta_{\mathrm{EC} 2,2020}$ & $\theta_{A C 1318}$ & $\theta_{\mathrm{EC} 2,2008}$ & $\theta_{\mathrm{MC} 10}$ & $\theta_{\mathrm{EC} 2,2020}$ & $\theta_{\mathrm{ACl318}}$ & $\theta_{\mathrm{EC} 2,2008}$ & $\theta_{\mathrm{MC} 10}$ & $\theta_{\mathrm{EC} 2,2020}$ & $\theta_{\mathrm{ACl} 1318}$ & $\theta_{\mathrm{EC} 2,2008}$ & $\theta_{\mathrm{MC} 10}$ & $\theta_{\mathrm{EC} 2,2020}$ & $\theta_{\mathrm{AC1318}}$ \\
\hline Count & & & & & & & & & & & & & & & & \\
\hline$\%$ most & & & & & & & & & & & & & & & & \\
\hline Average & & & & & 0.90 & 0.88 & 0.88 & 1.01 & 0.95 & 0.91 & 0.91 & 0.99 & 0.91 & 0.87 & 0.87 & 0.90 \\
\hline STdev & & & & & 0.10 & 0.10 & 0.10 & 0.13 & 0.07 & 0.07 & 0.07 & 0.07 & 0.14 & 0.14 & 0.14 & 0.15 \\
\hline $\mathrm{CoV}$ & & & & & $11 \%$ & $11 \%$ & $11 \%$ & $12 \%$ & $8 \%$ & $8 \%$ & $8 \%$ & $7 \%$ & $16 \%$ & $16 \%$ & $16 \%$ & $16 \%$ \\
\hline & & & & & & & & ycled con & te aggregat & & & & & & & \\
\hline & & $f_{c}: 10$ & $\mathrm{MPa}$ & & & $f_{c}: 30$ & $\mathrm{MPa}$ & & & $f_{c}: 50$ & $\mathrm{MPa}$ & & & $f_{c}: 70$ & $\mathrm{MPa}$ & \\
\hline & $\theta_{\mathrm{EC} 2,2008}$ & $\theta_{\mathrm{MC10}}$ & $\theta_{\mathrm{EC} 2,2020}$ & $\theta_{\mathrm{ACl} 1318}$ & $\theta_{\mathrm{EC} 2,2008}$ & $\theta_{\mathrm{MC} 10}$ & $\theta_{\mathrm{EC} 2,2020}$ & $\theta_{\mathrm{ACl} 1318}$ & $\theta_{\mathrm{EC} 2,2008}$ & $\theta_{\mathrm{MC10}}$ & $\theta_{\mathrm{EC} 2,2020}$ & $\theta_{\mathrm{ACl318}}$ & $\theta_{\mathrm{EC} 2,2008}$ & $\theta_{M C 10}$ & $\theta_{\mathrm{EC} 2,2020}$ & $\theta_{\mathrm{ACl} 1318}$ \\
\hline Count & & & & & & & & & & & & & & & & \\
\hline$\%$ most & & & & & & & & & & & & & & & & \\
\hline Average & 1.23 & 1.22 & 1.21 & 1.07 & 1.15 & 1.12 & 1.12 & 0.91 & 1.14 & 1.10 & 1.10 & 0.83 & & & & \\
\hline STdev & 0.18 & 0.19 & 0.19 & 0.23 & 0.11 & 0.10 & 0.10 & 0.09 & 0.05 & 0.05 & 0.05 & 0.04 & & & & \\
\hline CoV & $14 \%$ & $15 \%$ & $15 \%$ & $21 \%$ & $9 \%$ & $9 \%$ & $9 \%$ & $10 \%$ & $5 \%$ & $5 \%$ & $5 \%$ & $5 \%$ & & & & \\
\hline
\end{tabular}


Table A. 3: $f_{c}$ vs. $f_{c t}$ : Statistics of the $\phi 100 \mathrm{~mm}$ cylinders. More than 7 mixes only.

\begin{tabular}{|c|c|c|c|c|c|c|c|c|c|c|c|c|c|c|c|c|}
\hline & \multicolumn{16}{|c|}{ Crushed natural aggregates } \\
\hline & \multicolumn{4}{|c|}{$f_{c}: 10-30 \mathrm{MPa}$} & \multicolumn{4}{|c|}{$\mathrm{f}_{\mathrm{c}}: 30-50 \mathrm{MPa}$} & \multicolumn{4}{|c|}{$f_{c}: 50-70 \mathrm{MPa}$} & \multicolumn{4}{|c|}{$\mathrm{f}_{\mathrm{c}}: 70-90 \mathrm{MPa}$} \\
\hline & $\theta_{\mathrm{EC} 2,2008}$ & $\theta_{\mathrm{MC} 10}$ & $\theta_{\mathrm{EC} 2,2020}$ & $\theta_{\mathrm{AC} 1318}$ & $\theta_{\mathrm{EC} 2,2008}$ & $\theta_{\mathrm{MC} 10}$ & $\theta_{E C 2,2020}$ & $\theta_{A C 1318}$ & $\theta_{E C 2,2008}$ & $\theta_{\text {MC10 }}$ & $\theta_{E C 2,2020}$ & $\theta_{A C 1318}$ & $\theta_{E C C 2,2008}$ & $\theta_{\mathrm{MC} 10}$ & $\theta_{E C 2,2020}$ & $\theta_{\mathrm{ACC} 318}$ \\
\hline Count & \multicolumn{4}{|c|}{15} & \multicolumn{4}{|c|}{86} & \multicolumn{4}{|c|}{30} & \multicolumn{4}{|c|}{12} \\
\hline$\%$ most & \multicolumn{4}{|c|}{$20 \%$} & \multicolumn{4}{|c|}{$27 \%$} & \multicolumn{4}{|c|}{$23 \%$} & \multicolumn{4}{|c|}{$33 \%$} \\
\hline Average & 1.45 & 1.45 & 1.45 & 1.03 & 1.27 & 1.27 & 1.27 & 1.07 & 1.18 & 1.18 & 1.18 & 1.12 & 1.27 & 1.29 & 1.29 & 1.29 \\
\hline STdev & 0.19 & 0.19 & 0.19 & 0.10 & 0.20 & 0.20 & 0.20 & 0.15 & 0.14 & 0.14 & 0.15 & 0.14 & 0.08 & 0.08 & 0.08 & 0.08 \\
\hline $\mathrm{CoV}$ & $13 \%$ & $13 \%$ & $13 \%$ & $9 \%$ & $16 \%$ & $16 \%$ & $16 \%$ & $14 \%$ & $12 \%$ & $12 \%$ & $12 \%$ & $12 \%$ & $7 \%$ & $7 \%$ & $7 \%$ & $7 \%$ \\
\hline Skew & 1.33 & 1.33 & 1.33 & 0.01 & 0.41 & 0.41 & 0.41 & 0.20 & 0.41 & 0.41 & 0.38 & 0.42 & -0.37 & -0.39 & -0.39 & -0.39 \\
\hline Kurt & 1.78 & 1.78 & 1.78 & 0.33 & 0.43 & 0.43 & 0.43 & 0.53 & 1.00 & 1.00 & 0.92 & 1.18 & 0.90 & 1.21 & 1.21 & 1.21 \\
\hline$\theta$ Ed & 1.22 & 1.22 & 1.22 & 0.92 & 1.03 & 1.03 & 1.03 & 0.89 & 1.01 & 1.01 & 1.01 & 0.96 & 1.17 & 1.19 & 1.19 & 1.19 \\
\hline$\Delta$ abs & 0.20 & 0.20 & 0.20 & -0.02 & 0.00 & 0.00 & 0.00 & -0.05 & -0.01 & -0.01 & -0.01 & 0.02 & 0.14 & 0.16 & 0.16 & 0.25 \\
\hline \multirow[t]{4}{*}{$\Delta \mathrm{rel}$} & $16 \%$ & $16 \%$ & $16 \%$ & $-3 \%$ & $0 \%$ & $0 \%$ & $0 \%$ & $-6 \%$ & $-1 \%$ & $-1 \%$ & $-1 \%$ & $2 \%$ & $12 \%$ & $14 \%$ & $14 \%$ & $21 \%$ \\
\hline & \multicolumn{16}{|c|}{ Rounded natural aggregates } \\
\hline & \multicolumn{4}{|c|}{$f_{c}: 10-30 \mathrm{MPa}$} & \multicolumn{4}{|c|}{$\mathrm{f}_{\mathrm{c}}: 30-50 \mathrm{MPa}$} & & & & & & & & \\
\hline & $\theta_{\mathrm{EC} 2,2008}$ & $\theta_{\mathrm{MC} 10}$ & $\theta_{\mathrm{EC} 2,2020}$ & $\theta_{\mathrm{AC} 1318}$ & $\theta_{\mathrm{EC} 2,2008}$ & $\theta_{\mathrm{MC} 10}$ & $\theta_{\mathrm{ECC2,2020}}$ & $\theta_{A C 1318}$ & $\theta_{\mathrm{EC} 2,2008}$ & $\theta_{\mathrm{MC10}}$ & $\theta_{E C 2,2020}$ & $\theta_{\mathrm{AC} 1318}$ & $\theta_{\mathrm{EC} 2,2008}$ & $\theta_{\text {MC10 }}$ & $\theta_{\mathrm{EC} 2,2020}$ & $\theta_{A C 1318}$ \\
\hline Count & & & & & \multirow{2}{*}{\multicolumn{4}{|c|}{$\frac{13}{46 \%}$}} & & & & & & & & \\
\hline$\%$ most & & & & & & & & & & & & & & & & \\
\hline Average & & & & & 1.19 & 1.19 & 1.19 & 0.97 & & & & & & & & \\
\hline STder & & & & & 0.14 & 0.14 & 0.14 & 0.09 & & & & & & & & \\
\hline $\mathrm{CoV}$ & & & & & $12 \%$ & $12 \%$ & $12 \%$ & $10 \%$ & & & & & & & & \\
\hline Skew & & & & & 0.15 & 0.15 & 0.15 & 0.23 & & & & & & & & \\
\hline \multirow[t]{4}{*}{ Kurt } & & & & & -0.24 & -0.24 & -0.24 & -0.8 & & & & & & & & \\
\hline & \multicolumn{16}{|c|}{-0.24} \\
\hline & \multicolumn{4}{|c|}{$f_{c}: 10-30 \mathrm{MPa}$} & \multicolumn{4}{|c|}{$f_{c}: 30-50 \mathrm{MPa}$} & \multicolumn{4}{|c|}{$f_{c}: 50-70 \mathrm{MPa}$} & & & & \\
\hline & $\theta_{\mathrm{EC} 2,2008}$ & $\theta_{\mathrm{MC} 10}$ & $\theta_{E C 2,2020}$ & $\theta_{\mathrm{AC} 1318}$ & $\theta_{\mathrm{EC} 2,2008}$ & $\theta_{M C 10}$ & $\theta_{\mathrm{EC} 2,2020}$ & $\theta_{\mathrm{AC} 1318}$ & $\theta_{\mathrm{EC} 2,2008}$ & $\theta_{\text {MC10 }}$ & $\theta_{E C 2,2020}$ & $\theta_{\mathrm{AC} 1318}$ & $\theta_{E C 2,2008}$ & $\theta_{\mathrm{MC} 10}$ & $\theta_{\mathrm{EC} 2,2020}$ & $\theta_{\mathrm{ACI} 18}$ \\
\hline Count & & & & & & & & & & & & & & & & \\
\hline$\%$ most & & & & & & & & & & & & & & & & \\
\hline Average & 1.55 & 1.55 & 1.55 & 0.98 & 1.07 & 1.07 & 1.07 & 0.89 & 1.18 & 1.18 & 1.18 & 1.12 & & & & \\
\hline STder & 0.26 & 0.26 & 0.26 & 0.10 & 0.10 & 0.10 & 0.10 & 0.08 & 0.14 & 0.14 & 0.15 & 0.14 & & & & \\
\hline CoV & $17 \%$ & $17 \%$ & $17 \%$ & $10 \%$ & $9 \%$ & $9 \%$ & $9 \%$ & $9 \%$ & $12 \%$ & $12 \%$ & $12 \%$ & $12 \%$ & & & & \\
\hline Skew & 0.28 & 0.28 & 0.28 & 1.05 & 0.34 & 0.34 & 0.34 & 0.41 & 0.41 & 0.41 & 0.38 & 0.42 & & & & \\
\hline Kurt & -0.74 & -0.74 & -0.74 & 0.21 & -1.25 & -1.25 & -1.25 & 0.04 & 1.00 & 1.00 & 0.92 & 1.18 & & & & \\
\hline$\theta \mathrm{Ed}$ & 1.23 & 1.23 & 1.23 & 0.86 & 0.95 & 0.95 & 0.95 & 0.79 & 1.01 & 1.01 & 1.01 & 0.96 & & & & \\
\hline$\Delta$ abs & 0.25 & 0.25 & 0.25 & 0.04 & -0.03 & -0.03 & -0.03 & -0.03 & 0.03 & 0.03 & 0.03 & 0.14 & & & & \\
\hline$\Delta \mathrm{rel}$ & $20 \%$ & $20 \%$ & $20 \%$ & $5 \%$ & $-3 \%$ & $-3 \%$ & $-3 \%$ & $-3 \%$ & $3 \%$ & $3 \%$ & $3 \%$ & $14 \%$ & & & & \\
\hline
\end{tabular}


Table A.4: $f_{c}$ vs. $f_{c t}$ : Statistics of the $\phi 100 \mathrm{~mm}$ cylinders. More than 7 mixes only.

\begin{tabular}{|c|c|c|c|c|c|c|c|c|c|c|c|c|c|c|c|c|}
\hline & \multicolumn{16}{|c|}{ Crushed natural aggregates } \\
\hline & \multicolumn{4}{|c|}{$f_{c}: 10-30 \mathrm{MPa}$} & \multicolumn{4}{|c|}{$f_{c}: 30-50 \mathrm{MPa}$} & \multicolumn{4}{|c|}{$\mathrm{f}_{\mathrm{c}}: 50-70 \mathrm{MPa}$} & \multicolumn{4}{|c|}{$\mathrm{f}_{\mathrm{c}}: 70-90 \mathrm{MPa}$} \\
\hline & $\theta_{\mathrm{EC} 2,2008}$ & $\theta_{\mathrm{MC} 10}$ & $\theta_{\mathrm{EC} 2,2020}$ & $\theta_{A C 1318}$ & $\theta_{\mathrm{EC} 2,2008}$ & $\theta_{\mathrm{MC} 10}$ & $\theta_{E C 2,2020}$ & $\theta_{A C 1318}$ & $\theta_{E C 2,2008}$ & $\theta_{\mathrm{MC} 10}$ & $\theta_{E C 2,2020}$ & $\theta_{A C 1318}$ & $\theta_{E C 2,2008}$ & $\theta_{\mathrm{MC} 10}$ & $\theta_{E C 2,2020}$ & $\theta_{\text {ACI318 }}$ \\
\hline Count & \multicolumn{4}{|c|}{34} & \multirow{2}{*}{\multicolumn{4}{|c|}{$\frac{125}{14 \%}$}} & \multirow{2}{*}{\multicolumn{4}{|c|}{$\begin{array}{l}44 \\
18 \%\end{array}$}} & \multicolumn{4}{|c|}{36} \\
\hline & \multicolumn{4}{|c|}{$21 \%$} & & \multicolumn{3}{|c|}{$14 \%$} & & & & $18 \%$ & \multicolumn{4}{|c|}{$21 \%$} \\
\hline Average & 1.37 & 1.37 & 1.37 & 0.96 & 1.24 & 1.24 & 1.24 & 1.05 & 1.07 & 1.07 & 1.07 & 1.00 & 1.10 & 1.10 & 1.12 & 1.02 \\
\hline STder & 0.24 & 0.24 & 0.24 & 0.20 & 0.18 & 0.18 & 0.18 & 0.14 & 0.15 & 0.15 & 0.15 & 0.14 & 0.14 & 0.14 & 0.15 & 0.13 \\
\hline $\mathrm{CoV}$ & 0.18 & 0.18 & 0.18 & 0.21 & $14 \%$ & $14 \%$ & $14 \%$ & $14 \%$ & $14 \%$ & $14 \%$ & $14 \%$ & $14 \%$ & $13 \%$ & $13 \%$ & $13 \%$ & $13 \%$ \\
\hline Skew & -0.34 & -0.34 & -0.34 & -0.44 & 0.66 & 0.66 & 0.66 & 0.57 & 0.46 & 0.46 & 0.46 & 0.39 & 0.20 & 0.20 & 0.25 & 0.07 \\
\hline \multirow[t]{4}{*}{ Kurt } & 0.20 & 0.20 & 0.20 & 0.76 & 0.90 & 0.90 & 0.90 & 0.53 & 0.92 & 0.92 & 0.94 & 0.91 & 1.96 & 1.96 & 1.96 & 1.96 \\
\hline & \multicolumn{16}{|c|}{ Rounded natural aggregates } \\
\hline & \multicolumn{4}{|c|}{$\mathrm{f}_{\mathrm{c}}: 10-30 \mathrm{MPa}$} & \multicolumn{4}{|c|}{$\mathrm{f}_{\mathrm{c}}: 30-50 \mathrm{MPa}$} & & & & & & & & \\
\hline & $\theta_{\mathrm{EC} 2,2008}$ & $\theta_{\mathrm{MC} 10}$ & $\theta_{\mathrm{EC} 2,2020}$ & $\theta_{\mathrm{AC} 1318}$ & $\theta_{\mathrm{EC} 2,2008}$ & $\theta_{\mathrm{MC} 10}$ & $\theta_{\mathrm{EC} 2,2020}$ & $\theta_{A C 1318}$ & & & & & & & & \\
\hline Count & \multirow{2}{*}{\multicolumn{4}{|c|}{$\frac{14}{86 \%}$}} & \multirow{2}{*}{\multicolumn{4}{|c|}{$\frac{1 /}{71 \%}$}} & & & & & & & & \\
\hline & & & & & & & & & & & & & & & & \\
\hline Average & 1.36 & 1.36 & 1.36 & 0.92 & 1.24 & 1.24 & 1.24 & 1.05 & & & & & & & & \\
\hline STdev & 0.14 & 0.14 & 0.14 & 0.14 & 0.18 & 0.18 & 0.18 & 0.14 & & & & & & & & \\
\hline $\mathrm{CoV}$ & $11 \%$ & $11 \%$ & $11 \%$ & $15 \%$ & $14 \%$ & $14 \%$ & $14 \%$ & $14 \%$ & & & & & & & & \\
\hline Skew & 1.33 & 1.33 & 1.33 & 1.40 & 0.66 & 0.66 & 0.66 & 0.57 & & & & & & & & \\
\hline \multirow[t]{4}{*}{ Kurt } & 2.49 & 2.49 & 2.49 & 3.19 & 0.90 & 0.90 & 0.90 & 0.53 & & & & & & & & \\
\hline & \multicolumn{16}{|c|}{ Crushed recycled concrete aggregates } \\
\hline & \multicolumn{8}{|c|}{$\mathrm{f}_{\mathrm{c}}: 10-30 \mathrm{MPa}$} & \multirow{2}{*}{\multicolumn{4}{|c|}{$\mathrm{f}_{\mathrm{c}}: 50-70 \mathrm{MPa}$}} & & & & \\
\hline & $\theta_{\mathrm{EC} 2,2008}$ & $\theta_{M C 10}$ & $\theta_{\mathrm{EC} 2,2020}$ & $\theta_{\mathrm{AC} 1318}$ & $\theta_{\mathrm{EC} 2,2008}$ & $\theta_{\mathrm{MC} 10}$ & $\theta_{\mathrm{EC} 2,2020}$ & $\theta_{A C 1318}$ & & & $\theta_{E C 2,2020}$ & $\theta_{\mathrm{AC} 1318}$ & & & & \\
\hline Count & & & & & \multirow{2}{*}{\multicolumn{4}{|c|}{$\frac{46}{33 \%}$}} & \multirow{2}{*}{\multicolumn{4}{|c|}{$\frac{18}{61 \%}$}} & & & & \\
\hline & & & & & & & & & & & & & & & & \\
\hline Average & & & & & 1.09 & 1.09 & 1.09 & 0.91 & 0.96 & 0.96 & 0.96 & 0.90 & & & & \\
\hline STdev & & & & & 0.21 & 0.21 & 0.21 & 0.17 & 0.15 & 0.15 & 0.15 & 0.14 & & & & \\
\hline $\mathrm{CoV}$ & & & & & $19 \%$ & $19 \%$ & $19 \%$ & $18 \%$ & $16 \%$ & $16 \%$ & $16 \%$ & $16 \%$ & & & & \\
\hline Skew & & & & & 1.20 & 1.20 & 1.20 & 0.68 & 1.61 & 1.61 & 1.62 & 1.67 & & & & \\
\hline Kurt & & & & & 2.21 & 2.21 & 2.21 & 0.73 & 2.55 & 2.55 & 2.58 & 2.95 & & & & \\
\hline
\end{tabular}

